\title{
VÍctor CONDORI
}

\author{
Poder BRITÁNICO Y MERCADO EN AREQUIPA. \\ La Casa Jack, Hermanos y Compañía, 1824-1853 ${ }^{1}$
}

\begin{abstract}
RESUMEN
Este trabajo intenta conocer los inicios del comercio británico en la ciudad de Arequipa después de la separación política de España, a partir de las actividades de una de las casas comerciales más representativas Jack, Hermanos y Compañía, fundada por nativos de Escocia; asimismo, busca determinar las estrategias desarrolladas por esta firma durante más de treinta años de ejercicio profesional, en que llegaron a convertirse en una de las más importantes de la región de Arequipa y en una época marcada por la inestabilidad política y la angustia fiscal.
\end{abstract}

Palabras claves: Arequipa, siglo XIX, comercio, aduana, importaciones, exportaciones, Inglaterra.

\begin{abstract}
This article attempts to investigate the beginnings of the British trade in the city of Arequipa after the political separation from Spain, starting with the activities of one of the most emblematic commercial firm Jack, Brothers \& Company founded by natives from Scotland. Additionally, it looks to determine the strategies developed by this firm during more than thirty years of operation, in which they became one of the most important businesses in the Arequipa region in a period marked by political instability and financial distress.
\end{abstract}

Key words: Arequipa, Nineteenth Century, Customs, Importation, Exportation, England.

Recibido: Enero 2018.

Aceptado: Julio 2018.

\footnotetext{
* Magíster en Historia por la Universidad Católica San Pablo de Arequipa. Profesor e investigador en esa casa de estudios. Correo electrónico: jvcondori@ucsp.edu.pe

${ }^{1}$ Este trabajo forma parte de un proyecto de mayor alcance sobre el comercio extranjero en la región de Arequipa entre 1821 y 1850, el cual pudo realizarse gracias al Concurso de Proyectos de Investigación y Fondos Semilla 2018 de la Universidad Católica San Pablo.
} 
John C. Jack hijo de un herrero escocés, llegó a Arequipa una noche antes que yo. Sus modales reflejaban probablemente su origen. Sin embargo, era un hombre agradable, de buena contextura y un comerciante inteligente. Estableció en Arequipa la casa de Wyllie Miller

y Compañía y cuando algunos años después esta firma suspendió sus pagos en Valparaíso, él había administrado los negocios con tanta pericia que la sucursal de Arequipa no estaba, en lo más mínimo, comprometida en la quiebra. Luego se estableció solo bajo el nombre de Jack, Brothers \& Co. Y después de trabajar duro algunos años regresó a Inglaterra con una considerable fortuna...

Le dejó el negocio de Arequipa a su hermano James, quien también se hizo rico. Poco después, vino su hermano Charles, quien murió muy joven en la misma ocupación y ahora el negocio es administrado por el señor Church, cuñado de John y su casa en Arequipa continúa creciendo aún más que la de los Gibbs.

Heinrich Witt ${ }^{2}$

\section{INTRODUCCIÓN}

Con el inicio de las guerras de independencia, numerosos comerciantes extranjeros comenzaron a establecerse en distintas ciudades de América del Sur, como Rio de Janeiro, Montevideo, Buenos Aires y Valparaíso, alentados por las condiciones favorables que se presentaban, incluso, en aquellos territorios todavía bajo control de la corona española, como fue el caso del virreinato del Perú. Aunque tales "comerciantes aventureros" provenían de distintas naciones europeas, la comunidad más grande era originaria de Gran Bretaña, vale decir, ingleses y escoceses. Mientras algunos de ellos retornaron a Europa al cabo de unos pocos años, en posesión de una considerable fortuna o completamente arruinados, muchos otros terminaron estableciéndose en territorio americano, constituyendo importantes casas comerciales para dedicarse de manera ventajosa al negocio de la importación de efectos y exportación de materias primas. Muy al margen de la decadencia económica y la inestabilidad política experimentada en algunos países de América Latina durante la primera mitad del siglo XIX, un buen número de estas firmas comerciales extranjeras lograron salir a flote de manera exitosa y por varias generaciones.

Este fenómeno decimonónico se vivió en distintas ciudades de América del Sur, y Arequipa no fue la excepción, aunque con algunas particularidades. En esta región, no obstante, haberse establecido numerosas casas comerciales europeas desde por lo menos $1821 \mathrm{y}$ algunas de ellas sucursales de firmas bien establecidas en Lima o Valparaíso, como Gibbs Crawley, Dickson Price, Tayleur Mac Laughlin o Le Bris Bertehaume, la más notable de ellas fue una casa fundada por inmigrantes escoceses denominada Jack, Hermanos y Com-

\footnotetext{
${ }^{2}$ Heinrch Witt nació en la ciudad Altona cerca de Hamburgo en 1799, llegó a Arequipa como empleado de la Casa Gibbs \& Son de Londres en 1824 y residió en el Perú hasta su muerte en 1892. En sus sesenta y ocho años de vida peruana, recorrió numerosas regiones y fue testigo privilegiado de la vida política, económica y cultural del Perú decimonónico. Todas sus vivencias fueron registradas en un prolijo diario personal, el mismo que llegó a alcanzar más de diez volúmenes. En diciembre de 2015, la editorial holandesa Brill publicó los diez volúmenes del diario en inglés, sin complementos ni omisiones. Ulrich Mucke (ed.), The Diary of Heinrich Witt, Leiden, Editorial Brill, 2016. 10 vols.
} 
pañía. La misma que logró posicionarse durante varias décadas entre las más grandes e importantes de la región, tanto en relación con sus actividades de importación, comercialización y exportación de materias primas hacia Europa. Aunque esta negociación se mantuvo con diferentes denominaciones hasta por lo menos 1880, los años de mayor desarrollo y prosperidad se extendieron entre 1824 y 1853, los considerados en el presente estudio.

En ese sentido, ante la falta de investigaciones sobre el comercio británico en el Perú durante los tempranos años de la república, este trabajo busca conocer en la medida de nuestras posibilidades documentales y académicas, el inicio de la presencia británica en la ciudad; así como el proceso de formación, desarrollo y consolidación de la Casa Jack, Hermanos y Compañía y las estrategias desarrolladas por esta firma durante más de treinta años de ejercicio profesional, en que llegaron a convertirse en una de las más exitosas, de la historia económica de Arequipa, durante la primera mitad del siglo XIX.

\section{Arequipa A Fines de la Colonia}

En 1784, se introdujo en el Perú el sistema de intendencias, por el cual el territorio virreinal quedó dividido en siete circunscripciones, con sus respectivas autoridades políticas y militares, los intendentes. Una de esas circunscripciones fue la Intendencia de Arequipa, ubicada en la parte meridional del virreinato, que se extendía desde el valle de Acarí hasta el río Loa, en el actual norte chileno; estaba dividida en siete partidos o provincias, a saber: Arequipa o Cercado, Camaná, Condesuyos, Caylloma, Moquegua, Arica y Tarapacá ${ }^{3}$. Poseía la intendencia una extensa costa, apropiada para el comercio legal y de contrabando, pero muy pocos puertos, y los centros urbanos más resaltantes, después de la capital eran Camaná, Moquegua, Tacna y Arica, aunque con una población inferior a diez mil habitantes.

La capital de la antigua intendencia era la ciudad de Arequipa, "la muy noble y muy leal", "la fidelísima"; la ciudad más poblada del Perú después de Lima, con cerca de treinta y siete mil habitantes (de ella veintidós mil personas vivían en el centro de la ciudad y un $71 \%$ registrada como españoles), esta ciudad se ubica a medio camino entre la costa y la sierra, a una altitud de $2320 \mathrm{msnm}$. En las últimas décadas de gobierno colonial, la economía de la región estuvo relacionada con tres actividades fundamentales, la agricultura de exportación, el comercio y en menor medida la minería ${ }^{4}$.

\footnotetext{
${ }^{3}$ Acerca del sistema de intendencias en Hispanoamérica, existen numerosos trabajos, Luis Navarro García, Intendencia de Indias, Sevilla, Escuela de Estudios Hispanoamericanos de Sevilla, 1959; Gisella Morazzani de Pérez Enciso, La Intendencia en España y América, Caracas, Universidad Central de Venezuela, 1966; John Lynch, Administración colonial española, 1782-1810. El sistema de Intendencias en el virreinato del Río de la Plata, Buenos Aires, Editorial Universitaria, 1967; Ricardo Rees Jones, El despotismo ilustrado y los intendentes de la Nueva España, México, Universidad Nacional Autónoma de México, 1979 y Horst Pietschmann, Las reformas borbónicas y el sistema de intendencias en Nueva España, México, Fondo de Cultura Económica, 1996; pero sobre el Perú, hasta ahora, Carlos Deustua Pimentel, Las intendencias en el Perú, 1790-1796, Sevilla, Escuela de Estudios Hispanoamericanos de Sevilla, 1965 y John Fisher, Gobierno y sociedad en el Perú colonial. El régimen de las intendencias, 1784-1814, Lima, Pontificia Universidad Católica del Perú, 1981.

${ }^{4}$ El tema de la economía arequipeña tardo-colonial se ha trabajado en John Wibel, The Evolution of a Regional Community within Empire Spanish and Peruvian Nation Arequipa 1780-1845, Ph.D. thesis, Stan-
} 
La riqueza agrícola descansaba en el cultivo de la vid, insumo básico para la elaboración de los afamados vinos y aguardientes en los cercanos valles de Vitor, Majes y Moquegua, además de ser la fuente principal de la fortuna y prestigio de cientos de familias arequipeñas; a principios del siglo XIX la producción de vinos alcanzó las quinientas mil botijas. Esta considerable producción, en un $90 \%$ era utilizada para la elaboración de aguardiente de uva que se comercializaba en ciudades, pueblos y sobre todo, centros mineros de la Intendencia, el sur del Perú y la Audiencia de Charcas, como: Potosí, Oruro, La Paz, Puno, Cuzco, Condesuyos y Caylloma. A través de esta lucrativa actividad, la economía arequipeña se integró en un amplio circuito de intercambio regional sino, sobre todo, pudo obtener el siempre escaso capital monetario, imprescindible, para adquirir productos regionales como: azúcar, coca, tejidos de obrajes, lana, algodón, carne, cueros, jabón, velas y mulas para el transporte; además de las codiciadas mercancías extranjeras, como los tejidos de distintos tipos y calidades.

De forma paralela, las últimas décadas del siglo XVIII fueron testigos de una notable expansión del comercio de los llamados "efectos de Castilla", gracias a diversos factores como: la política de liberación de puertos introducida por los Borbones en 1778 (que incluía al puerto de Arica dentro de los veinticuatro puertos liberados para el comercio directo con la Península), el establecimiento de una factoría de la mayor empresa comercial de este siglo, los Cinco Gremios Mayores de Madrid ${ }^{5}$ y a una importante migración vasco-navarra hacia la región de Arequipa, proveídos de nuevas ideas en materia empresarial y sólidos vínculos comerciales en ciudades como: Lima, Valparaíso, Buenos Aires y Cádiz. Estos "nuevos conquistadores españoles" lograron integrarse dentro de las familias tradicionales a través de sendos matrimonios y en poco tiempo consolidaron una base económica y social bastante compacta, una verdadera comunidad de intereses en las postrimerías del gobierno colonial en América.

Con la consolidación de la Independencia en la región, a partir de 1825, la Intendencia de Arequipa se denominó Departamento y el Intendente fue reemplazado por una nueva autoridad política y militar, nombrada por el gobierno central de Lima, el Prefecto. Aunque por otro lado, siguió ocupando el mismo territorio y manteniendo las mismas provincias, no pudo conservar su prosperidad económica tradicional, ni su singular composición social. La primera de ellas, debido a los efectos negativos causados por la guerra de independencia sobre actividades como la agricultura y la minería y la segunda, que influyó en la primera, a raíz de la progresiva migración de población europea.

ford University, 1975; Eusebio Quiroz Paz-Soldán, Aspectos económicos de la Independencia de Arequipa 1790-1830, tesis de Doctor, Arequipa, Universidad Nacional de San Agustín, 1976; Kendall Brown, Borbones y aguardiente. La reforma imperial en el sur andino. Arequipa en vísperas de la Independencia, Lima, Banco Central de Reserva del Perú-Instituto de Estudios Peruanos, 2008; Carlos Buller, Vinos, aguardiente y mercado. Auge y declive de la economía del vino en los valles de Arequipa (1770-1853), Lima, Editorial Quellca, 2011 y Víctor Condori, "Entre la bonanza y la crisis. Los Cinco Gremios Mayores de Madrid en Arequipa (1790-1820)", en Revista Complutense de Historia de América, vol. 40, Madrid, 2014, pp. 203-231.

${ }^{5}$ Con relación a las actividades de la Compañía General de los Cinco Gremios Mayores de Madrid en la región, véase Víctor Condori, Reformas económicas y privilegios comerciales. Los Cinco Gremios Mayores de Madrid en Arequipa, 1790-1820, Arequipa, Fondo Editorial de la Universidad Católica San Pablo, 2014 y "Entre la bonanza...", op. cit., pp. 203-231. 


\section{LOS PRIMEROS COMERCIANTES EXTRANJEROS}

Muy a pesar de las prohibiciones reales durante los primeros siglos de gobierno colonial, para fines del XVIII el comercio con extranjeros gozaba de buena salud y se encontraba extendido a lo largo y ancho del virreinato peruano. Los pueblos y ciudades, particularmente de la costa, estuvieron muy familiarizados con él, al punto que fue frecuente observar por aquellos años en algún puerto o caleta del litoral, uno o más navíos extranjeros a la espera de cualquier autorización oficial para dar inicio a sus lucrativas actividades. En la misma magnitud, no se puede dejar de mencionar el comercio clandestino o de contrabando, cuya práctica fue tan antigua como el propio monopolio comercial.

Dicho comercio, a principios del siglo XIX, provenía de Inglaterra, Francia y Estados Unidos. Aunque, el coloso del norte era en apariencia el más joven de los tres, había venido aprovechándose de los mercados americanos desde fines del siglo XVIII, cuando España abrió sus puertos coloniales a los llamados países neutrales ${ }^{6}$. En efecto, desde 1795 existía un tratado de Amistad, Límites y Navegación entre España y Estados Unidos $^{7}$. No era de extrañar que bajo esa misma modalidad Inglaterra y Francia hayan obtenido grandes beneficios económicos de España en épocas anteriores. Empero, a partir de la invasión napoleónica a la Península en 1808, y hasta la independencia completa del Perú en diciembre de 1824, las mayores ventajas las obtuvieron comerciantes y empresarios de la ahora "aliada", monarquía británica. En ese sentido, el 22 de julio de 1818, una junta permanente de arbitrios convocada por el virrey Joaquín de la Pezuela (1816-1821), propuso "el comercio libre con los ingleses por el término de dos años pagando un 12\% sobre los derechos comunes" oposición del monopólico Tribunal del Consulado de Lima. Sin embargo, el permanente estado de guerra de los últimos años y las necesidades de mercancías, insumos, armas y, por supuesto, ingresos cada vez más urgentes del gobierno colonial, llevaron al Virrey a otorgar permisos especiales a los capitanes o sobrecargos de los barcos mercantes extranjeros fondeados en la rada del Callao, también, a decretar el "comercio libre para los extranjeros en el Perú", a partir del año $1820^{9}$. Tal medida, en la práctica, significó la llegada de comerciantes, negociantes y aventureros de distintas regiones de Europa.

Con el bloqueo del puerto del Callao por la armada patriota y la toma de la ciudad de Lima por fuerzas chileno-argentinas en julio de 1821, el epicentro de este importantísimo comercio se extendió más al sur, a la intendencia de Arequipa; la misma que se convirtió en el principal centro de abastecimiento del último virreinato de América y su

\footnotetext{
${ }^{6}$ Arthur P. Whitaker, Estados Unidos y la Independencia de América Latina (1800-1830), Buenos Aires, Editorial Universitaria, 1964, p. 18.

${ }^{7}$ Cristina Mazzeo (comp.), Los comerciantes limeños a fines del siglo XVIII. Capacidad y cohesión de una elite 1750-1825, Lima, Pontificia Universidad Católica del Perú, 2000, p. 14.

${ }^{8}$ Sobre las disputas por el comercio libre en el Perú, Patricia Marks, Deconstructing Legitimacy. Viceroys, Merchants, and the Military in Late Colonial Peru. Pennsylvania, The Pennsylvania State University Press, 2007, pp. 219-263. Asimismo, Cristina Mazzeo, "El Consulado de Lima y la política comercial española 1806-1821", en Bernd Hausberger y Antonio Ibarra (eds.), Los consulados de comerciantes. Siglos XVII-XIX, Madrid, Biblioteca Ibero-Americana, 2003, vol. 93, p. 216.

${ }^{9}$ Deolinda Villa Esteves, "La elite comercial limeña entre el comercio libre y la Guerra de la Independencia El caso de Antonio de Elizalde”, en Mazzeo (comp.), Los comerciantes limeños..., op. cit., p. 168.
} 
puerto Quilca, en la puerta de ingreso para toda clase de mercancías extranjeras hasta fines de 1824. Esta nueva posición de la ciudad de Arequipa, favorecida por las condiciones de guerra, atrajo en poco tiempo a un buen número de mercaderes ${ }^{10} \mathrm{y}$ permitió el establecimiento de numerosas casas comerciales extranjeras, principalmente inglesas, que para el año 1824 sumaban cerca de dieciséis y más de tres millones de pesos las inversiones en créditos y propiedades ${ }^{11}$.

La determinación de abrir el mercado virreinal al comercio extranjero se vio favorecido, en primer término, por la nula presencia de barcos españoles durante aquellos años $\mathrm{y}$, en segundo, por las necesidades del gobierno colonial de conseguir ingresos, suministros y particularmente armas, para así enfrentar de manera decisiva a las fuerzas patriotas acantonadas en la costa central. En ese sentido, el gobierno del Cuzco buscó obtener el máximo provecho. En 1824, el último virrey del Perú, José de la Serna, (1821-1824), estableció el real derecho de alcabala sobre las mercancías importadas, impuesto que alcanzó el 34\% sobre el monto principal ${ }^{12}$. La medida no pudo ser más acertada (véase cuadro $\mathrm{N}^{\mathrm{o}} 1$ ). En noviembre de ese mismo año la Tesorería de Aduanas de Quilca, remitió a la Caja Nacional de la ciudad de Arequipa más de cuarenta y siete mil pesos, pertenecientes solo a los derechos "que tiene colectados de los comerciantes extranjeros" en los primeros meses ${ }^{13} \mathrm{y}$ a lo largo de ese año, el comerciante español Lucas de la Cotera, introdujo mercancías por más de quinientos mil pesos ${ }^{14}$.

\section{CUADRO $\mathrm{N}^{\mathrm{o}} 1$ \\ Ingresos de la Caja Real de Arequipa durante la Independencia (en pesos)}

\begin{tabular}{|c|c|}
\hline Año & Valor de importaciones \\
\hline 1821 & 9105 \\
\hline 1822 & 18824 \\
\hline 1823 & - \\
\hline 1824 & 389641 \\
\hline 1825 & 225778 \\
\hline
\end{tabular}

Fuente: Quiroz, op. cit.

\footnotetext{
${ }^{10}$ Heinrich Witt, Diario 1824-1890. Un testimonio personal sobre el Perú del siglo XIX, Lima, Banco Mercantil, 1992, vol. I, pp. 61-69.

${ }^{11}$ Robert A. Humphreys (ed.), British Consular Reports on the trade and politics of Latin America, 18241826, London, Offices of the Royal Historical Society, pp. 108 y 116.

${ }^{12}$ En enero de 1824, el comerciante español Lucas de la Cotera, recibió en consignación el cargamento del bergantín inglés Swallon, valorizado en 38282 pesos, teniendo que abonar 13015 pesos por ese real derecho. En Archivo Regional de Arequipa (en adelante ARAR), Intendencia, Causas Administrativas 108, 27 de enero de 1824.

${ }^{13}$ ARAR, Caja Nacional de Hacienda, Libro Mayor 1824, Otras Tesorerías.

${ }^{14}$ El español Lucas de la Cotera fue el más importante e influyente comerciante de Arequipa entre 18211824, sus buenas relaciones con las autoridades españolas, incluida su amistad con el propio virrey José de la Serna y sus enormes ingresos, lo llevaron a convertirse en el principal abastecedor y financista del gobierno virreinal en la agonía de su presencia en el Perú. Sobre sus actividades en Arequipa durante esta época, Víctor Condori, "Guerra y economía en Arequipa: las actividades del español Lucas de la Cotera en una coyuntura de crisis, 1821-1824”, en Revista de Indias, vol. LXXI, № 253, Madrid, 2011, pp. 827-858.
} 
En relación con los comerciantes extranjeros, se debe señalar que la mayor parte de ellos llegaron a Arequipa provenientes de Inglaterra, como sobrecargos, consignatarios o representantes de alguna casa comercial ya establecida ${ }^{15}$, y pese a residir en la ciudad desde por lo menos 1821; fue a partir de 1823 que empezaron a multiplicar sus actividades mercantiles, a decir de los registros notariales hallados en los archivos de la ciu$\mathrm{dad}^{16}$, y un año después, según estos mismos documentos, se percibe un proceso gradual de desplazamiento de los comerciantes locales, tanto criollos como peninsulares, hasta tomar el control absoluto de la economía local y regional, una década más tarde. Durante estos primeros años de residencia en Arequipa, los citados comerciantes se dedicaron de manera muy ventajosa a diversas actividades. Además de continuar como representantes de alguna firma ${ }^{17}$ o recibir toda clase de poderes ${ }^{18}$, la más extendida y lucrativa de ellas, consistió en abrir sus propias tiendas o almacenes en la ciudad para dedicarse a la venta de efectos europeos al por mayor y menor ${ }^{19}$ a comerciantes, de la localidad y de ciudades como Cuzco, Puno, La Paz y Cochabamba ${ }^{20}$.

Una de las tantas ventajas con las que contaban tales comerciantes en relación con sus homólogos locales, además de sus vínculos con poderosas firmas en Londres, Liverpool o Valparaíso o algún supuesto talento mercantil, era la de no estar forzados a contribuir con algún préstamo o donativo y mucho menos ser blanco de las permanentes confiscaciones perpetradas por el gobierno virreinal a fin de paliar sus frecuentes necesidades pecuniarias. Sin embargo, tampoco fueron indiferentes a tales necesidades o requerimientos. Así, de manera ocasional, proporcionaban sumas importantes en calidad de préstamo o proveían de suministros al ejército realista. Como aquel entregado en noviembre de 1824, por Luis Stevenson, Guillermo Turner y Santiago Ygualt, por valor de 1071 pesos en paños y caserillo, para "el vestuario del batallón de cazadores del rey"21,

\footnotetext{
${ }^{15}$ Entre los principales sobrecargos convertidos más tarde en residentes de la ciudad, se tiene a: Daniel Schütte, Anthon von Lotten, Juan Robinson, Samuel B. Mardon, Thomas N. Crompton, Santiago Ygualt y Roberto Page.

16 "Obligación de 1.584 pesos, don Mariano Pastor a favor de don Luis Stevenson y don Guillermo Turner de este comercio", en ARAR, Protocolos Notariales, Manuel Primo de Luque 720, fol. 1047.

17 "Don Santiago Ygualt, capitán y sobrecargo del bergantín inglés Bruce", en ARAR, Intendencia, Causas Administrativas 108, 24 de diciembre de 1824. "A Don Tomas Crompton, sobrecargo de la fragata Wavertrec, abonados 8.713 pesos...", en ARAR, Caja Nacional de Hacienda, Libro Mayor de la Caja de Arequipa 20, 29 de diciembre de 1824.

18 "Poder general, Don Lucas de la Cotera a Don Guillermo Cochran", en ARAR, Protocolos Notariales, Manuel Primo de Luque 721, fol. 947; "Poder general. Don Fernando Areveche a don Tomas Crompton de este comercio", fol. 972 y "Poder Don Samuel Gibbson a Don Luis Stevenson, residente en esta ciudad", en ARAR, Protocolos Notariales, Nazario de Rivera 822, fol. 213.

19 "Obligación de 8.950 pesos. Don Luis Gamez a favor de Don Tomas Crompton", en ARAR, Protocolos Notariales, Manuel Primo de Luque 721, fol. 846 y "Don Buenaventura Zereceda de este comercio a favor de Don Tomás Crompton la cantidad de 5.477 pesos, resto de mayor cantidad que les debía, importe de varios efectos de Castilla que le vendió a su entera satisfacción y a precios corrientes de plaza, por el término de 3 meses", en ARAR, Protocolos Notariales, Manuel Primo de Luque 721, 16 de octubre de 1824, fol. 847.

20 "Don Carlos Carazas, vecino de la ciudad del Cusco a la voluntad de Samuel B. Mardon de este comercio, en ARAR, Protocolos Notariales, Manuel Primo de Luque 720, fol. 905; "Don Manuel Gandarillas, vecino de Cochabamba a favor de Don Roberto Page de nación inglesa", en ARAR, Protocolos Notariales, Nazario de Rivera 822, fol. 316; "Obligación de 5.873 pesos. Don Salvador García vecino y del comercio de Cochabamba y Don Domingo Cuadros, a favor de Don Samuel B. Mardon”, en ARAR, Protocolos Notariales, Manuel Primo de Luque 721, fol. 953.

${ }^{21}$ ARAR, Caja Nacional de Hacienda, Libro Mayor 1824, fol. 51.
} 
o aquel otro, proporcionado un mes después por Ambrosio Ibáñez y Juan Moens de 12364 pesos, "que importaron los efectos suministrados al batallón Real Felipe y a los escuadrones de cazadores, dragones y voluntarios de la costa para vestuario"22.

\section{LOS INICIOS DEL COMERCIO BRITÁNICO EN AREQUIPA}

Aunque varios comerciantes ingleses residían en Arequipa desde inicios de la década de 1820 , en los primeros años sus actividades estuvieron limitadas por el control del comercio de importaciones de parte del mayor consignatario de aquellos años, el español Lucas de la Cotera; quien, gracias a sus vínculos políticos con las autoridades locales y sus fuertes contribuciones al gobierno virreinal, pudo monopolizar la casi totalidad de cargamentos extranjeros que llegaban a la región e introducir cerca de quinientos mil pesos en mercancías al año. Tal fue su ascendiente, que algunos comerciantes extranjeros se vieron en la necesidad de utilizar sus influencias y garantías ante las autoridades españolas para poder internar ciertas mercancías o salvaguardarlas de algún intento de confiscación ${ }^{23}$.

En ese sentido, las verdaderas oportunidades para los nuevos comerciantes se presentaron a partir de 1824, siendo uno de los hechos determinantes en este proceso la derrota de los ejércitos realistas en los campos de Ayacucho en diciembre de ese mismo año, que obligó la salida precipitada de algunos empresarios españoles, muy cercanos al virrey José de la Serna, entre los que se encontraba el propio Lucas de la Cotera. En realidad, este desplazamiento de los comerciantes peninsulares por extranjeros fue un fenómeno bastante extendido en Latinoamérica durante aquellos tempranos años. Así, entre 1825 y 1828 , se vivió una verdadera Belle Époque para aquellos comerciantes británicos establecidos en la región desde hacía casi un lustro, como: Thomas Crompton, Guillermo Hodgson, Roberto Page, Santiago Ygualt, Samuel B. Mardon, Guillermo Turner, Federico Marriot, Juan Robinson, Luis Stevenson, Samuel Haigh, entre otros. Muchas de cuyas actividades se vieron favorecidas no solo por una mayor apertura comercial de parte de las autoridades republicanas de Lima o sus nuevos vínculos con la élite política y social de la región, sino, también, por una verdadera avalancha de productos europeos introducidos por incontables barcos mercantes a través del modesto puerto de Quilca. Así lo sintetizó, también, el cónsul inglés Charles Milner Ricketts ${ }^{24}$, en su informe sobre el comercio del Perú en 1826:

\footnotetext{
${ }^{22}$ ARAR, Caja Nacional de Hacienda, Libro Mayor 1824, Hacienda Común, fol. 114.

23 "Fianza de juzgado y sentenciado. Don Lucas de la Cotera a favor de Don Santiago Ygualt", en ARAR, Protocolos Notariales, Manuel Primo de Luque 721, fol. 709; "Fianza de Don Lucas de la Cotera por Don Jeremías Sullivan, Don Guillermo Hodgson y Don Nicolás Matzon”, en ARAR, Protocolos Notariales, Manuel Primo de Luque 721, fol. 764. Además, “A Don Lucas de la Cotera reconocidos en deuda a su favor por tantos que se debe reintegrar a Don Tomas Crompton sobrecargo de la fragata Wavertrec", en ARAR, Libro Mayor de la Real Caja de Arequipa 20, Hacienda Común, fol. 29, 24 de diciembre de 1824.

${ }^{24} \mathrm{La}$ importancia del comercio e inversiones británicas en el Perú, llevó al gobierno inglés a nombrar en octubre de 1823, un cónsul general (Thomas Rowcroft) y un vicecónsul para Arequipa (Udney Passmore). Lamentablemente, Thomas Rowcroft murió de forma accidental en diciembre de 1824, siendo reemplazado Charles Milner Rickkets (1825-1830). Udney Passmore se mantuvo en el cargo hasta 1837, año en que fue reemplazado por el comerciante Thomas Crompton, como cónsul interino. Acerca de los cónsules británicos en Latinoamérica, revisar, Humphreys, op. cit., pp. XVIII y XIX.
} 
"Al estallar la revolución, el éxito de los primeros comerciantes ingleses fue muy grande; todos los artículos importados tenían demanda, y había presión para remitir la riqueza acumulada, por aquellos que buscaban dejar el país; las monedas de oro y plata, y los ornamentos, fueron sacados de los lugares donde habían sido escondidos; el capitán (capital) británico estaba maravillado ante las riquezas que recibía y se difundieron las más exageradas versiones sobre la riqueza del país" 25 .

En medio de esta vorágine, de relativos éxitos, se formaron numerosas empresas comerciales y mineras que tuvieron su origen en el mercado de capitales de Londres, muchos de cuyos representantes eran los mencionados comerciantes ingleses. Lamentablemente, algunas de ellas no alcanzaron el éxito estimado, terminando disueltas al poco tiempo de haberse constituido ${ }^{26}$. De este modo, para fines de la década de 1820, la mayor parte de los tempranos comerciantes ingleses como: Thomas Crompton, Guillermo Hodgson, Roberto Page, Santiago Ygualt, Luis Stevenson y Samuel Haigh, habían desaparecido de los primeros planos o, bien, porque regresaron a Europa, cambiaron de actividad o se trasladaron a otras ciudades como Lima o Tacna. En consecuencia, las actividades mercantiles en Arequipa fueron cayendo bajo control de las grandes casas comerciales, más afianzadas y con vínculos económicos y representantes en: Lima, Valparaíso, Baltimore, Liverpool, Londres, Burdeos, Hamburgo y Bremen; como las inglesas: Jack Hermanos, Gibbs-Crawley, Tayleur-Mac Laughlin, Dickson-Price, Turner-Marriot, Juan Moens y Juan Robinson; la francesa de Santiago Le Bris y la alemana de Cristóbal Guillermo Schütte.

Pese a estar impedidos por ley a expender sus mercancías al menudeo y en las provincias del departamento ${ }^{27}$, aquellas firmas terminaron monopolizando los principales cargamentos provenientes de Europa y Estados Unidos, la comercialización de tales efectos sobre una vasta región del sur andino, los empréstitos y socorros al gobierno local, el apoyo a obras sociales y filantrópicas ${ }^{28}$ y la extracción de metales preciosos en moneda corriente, pasta, polvo y chafalonía con destino al extranjero ${ }^{29}$. Una década después, habían tomado el control absoluto del comercio regional.

${ }^{25}$ Heraclio Bonilla (comp.), Gran Bretaña y el Perú 1826-1919: Informes de los cónsules británicos, Lima, Instituto de Estudios Peruanos-Fondo del Libro del Banco Industrial del Perú, 1975, vol. I, p. 22.

26 "Cancelación de compañía de minas", en ARAR, Protocolos Notariales, Manuel Primo de Luque 724, fol. 279.

${ }^{27}$ Un reglamento de comercio dado por el gobierno de Agustín Gamarra en enero de 1830, obligaba a los comerciantes extranjeros a trasladar sus tiendas o almacenes "a las poblaciones más inmediatas a los puertos mayores de la república". Ante la falta de condiciones de almacenamiento en el puerto de Islay, se les permitió establecerse en la ciudad de Arequipa; aunque con la tácita prohibición de realizar sus ventas al por menor y, peor aún, en las provincias del interior, para, de esta forma, no entrar en franca competencia con los menos poderosos y bastante recelosos comerciantes locales. Víctor Condori, "El francés Santiago Le Bris y la primera casa comercial extranjera en Arequipa 1821-1850", en Bulletin de l'Institut Français d'Études Andines vol. 42, N² 2, Lima, 2013, p. 267.

${ }^{28}$ En 1828, la compañía cómica de teatro provisional de Arequipa presentaba a beneficio del Colegio de la Independencia, el drama titulado Misantropía o Arrepentimiento. Los palcos fueron ocupados por: Juan Jack, Guillermo Schütte, Santiago Le Bris, Federico Marriot, Juan Robinson, Federico Johnson y Udny Passmore, quienes aportaron la suma de diez pesos por cada palco, frente a los seis y cuatro pesos del resto. Periódico El Republicano, tomo 3, No 32, Arequipa, 9 de agosto de 1828.

${ }^{29}$ Aunque no se cuenta con datos completos para estos primeros años, sí es posible reconstruir las exportaciones de metales desde Arequipa en décadas posteriores, como, por ejemplo, el año 1846, cuando se extrajo por el puerto de Islay 22079 marcos de plata piña, 3301 marcos de plata chafalonía, 7473 onzas de oro en pasta y polvo, 1530 onzas de oro selladas y 133.446 pesos en plata amonedada. Periódico El Republicano, tomo 20, Arequipa, enero-diciembre 1846. 


\section{La CAsa Jack en Arequipa}

Como algunos negociantes independientes, vale decir, que no llegaron contratados por ninguna de las casas comerciales ya instaladas en Arequipa como Gibbs Crawley, Tayleur-Mac Laughlin o Le Bris-Bertehaume y sin ningún vínculo mercantil en importantes ciudades como Lima o Valparaíso, Juan Jack, natural de Elgin Escocia, se estableció en esta ciudad a principios de noviembre de 1824, un mes antes de la derrota definitiva del ejército español en los campos de Ayacucho ${ }^{30}$. Muy probablemente, al igual que muchos de sus compatriotas, arribó como consignatario, comisionista o consignee, como los denominó Gabriel Salazar ${ }^{31}$, es decir, representante de una firma comercial en Liverpool, encargado de la misión de transportar una determinada carga de efectos hacia cualquier mercado de Latinoamérica, con el objetivo de comercializarla en las mejores condiciones, remitir, luego, el producto de la venta en plata o materias primas y obtener a cambio una buena comisión.

Luego de reconocer las condiciones económicas de la región, Juan Jack decidió probar fortuna estableciéndose en este departamento. En octubre de 1825, alquiló un espacioso local ubicado en la calle de La Merced, a pocos metros de la plaza principal de Arequipa, compuesto por dos tiendas, tres almacenes, un cuarto frente a la calle y dos cuartos interiores, pagando seiscientos pesos anuales por este concepto ${ }^{32}$. Al parecer, el inmueble sería utilizado de forma exclusiva como tienda-almacén, pues en enero del año siguiente alquiló una casa-vivienda en la calle San Juan de Dios por cinco años y seicientos pesos anuales ${ }^{33}$.

Después de algunos años de arduo trabajo, Juan Jack comenzó a figurar entre los principales comerciantes extranjeros de la ciudad, tanto por el valor de sus importaciones $^{34}$ como por el volumen de sus ventas ${ }^{35}$, además de sus permanentes contribuciones al gobierno local, a fin de atender "sus urgentes necesidades" 36 . Este ascenso mercantil

\footnotetext{
${ }^{30}$ Witt, op. cit., vol. I, pp. 54 y 61.

${ }^{31}$ Con relación a tales agentes del comercio británico este importante historiador chileno señala que los consignatarios eran en su mayoría jóvenes de modesto capital que iban a buscar fortuna en el extranjero. Algunos de ellos estuvieron relacionados con las grandes compañías comerciales británicas a través del parentesco - parientes jóvenes y de confianza-, cuyas comisiones no eran superiores al $15 \%$ del valor de las mercancías consignadas. Acerca de este tema, véase el capítulo II del libro de Gabriel Salazar Vergara, Mercaderes, empresarios y capitalistas (Chile, siglo XIX), Santiago, Penguin Random House, 2018.

32 “Arrendamiento de casa. Doña María del Carmen Bustamante a Don Juan Jack", en ARAR, Protocolos Notariales, Manuel Primo de Luque 722, fol. 641.

33 "Arrendamiento de casa-vivienda. Doña María Uzátegui vecina y mujer legítima de Don Cayetano Ribault a Don Juan Yaque (Jack)”, en ARAR, Protocolos Notariales, Manuel Primo de Luque 723, fol. 68.

34 "Enterado por Don Mariano Aréstegui a nombre de Don Juan Jack para que le sean abonado por la Aduana de Islay a cuenta de los derechos mercantiles", en ARAR, Tesorería de Arequipa, Libro Manual 31, 12 de febrero de 1831.

35 "Obligación. Don Pedro José Gamio vecino y del comercio a Don Juan Jack del comercio de esa ciudad, por la cantidad de 26.446 pesos, valor de varios efectos que le ha vendido", ARAR, Protocolos Notariales, Matías Morales 750, fol. 422.

${ }^{36}$ En enero de 1828, el prefecto del departamento de Arequipa solicitó un préstamo a los comerciantes de la localidad según la capacidad económica, sobresaliendo Juan Jack con tres mil pesos, Samuel B. Mardon con dos mil y el resto de comerciantes con mil pesos cada uno. ARAR, Tesorería de Arequipa, Libro Manual 25,1 de enero de 1828 .
} 
le permitió entrar en contacto con las grandes firmas importadoras del mayor centro de comercio europeo en el Pacífico sur, el puerto de Valparaíso ${ }^{37}$. Como consecuencia de ello, a inicios de 1830 abrió en la ciudad de Arequipa una dependencia de la poderosa casa comercial inglesa Wyllie, Miller y Compañía ${ }^{38}$, la misma que manejó con notable eficiencia y provecho, al punto que en 1832 se convirtió en socio de ella, pasando, la empresa, a denominarse Wyllie, Jack y Compañía ${ }^{39}$. Cuando, algunos años más tarde la casa matriz de Valparaíso entró en una grave recesión, suspendiendo sus pagos y consignaciones ${ }^{40}$, la sucursal de Arequipa, según Heinrich Witt "no estaba en los más mínimo comprometida con la crisis" 41 .

La experiencia obtenida y los vínculos con otros destacados centros de comercio, aunada a la crisis de la casa matriz chilena, llevó a Jack a separarse de dicha firma y establecer su propia empresa, bajo la denominación de Juan C. Jack en junio de $1835^{42}$. Al año siguiente, ya en sociedad con sus menores hermanos Santiago y Carlos, fundó la Casa Jack, Hermanos y Compañía, la misma que tendría su sede principal en la ciudad de Liverpool y una única dependencia en Arequipa, la que estaría encargada de importar toda clase de mercancías europeas sino, también, de exportar cotizadas materias primas como lana de camélidos y cascarilla; además de grandes volúmenes de metales preciosos, en polvo, pasta y moneda. Para el buen funcionamiento de la nueva empresa, Juan decidió establecerse en Liverpool a la cabeza de los negocios, mientras su hermano Santiago se haría cargo de administrar la filial arequipeña y organizar el comercio de lanas ${ }^{43}$.

A partir de esta fecha, la Casa Jack Hermanos experimentó un proceso de expansión notable que la llevó a convertirse en la más importante casa comercial extranjera de la región y por las próximas dos décadas y a su nuevo administrador, Santiago, en un hombre "extremadamente rico". No en vano, el alemán Heinrich Witt siempre reticente a reconocer los talentos de sus contemporáneos, refiriéndose a Santiago Jack decía que era hombre vulgar "pero un excelente comerciante" talento comercial de Jack que, en reiteradas ocasiones le propuso asociarse para abrir un

37 "Poder General. Don Juan Jack del comercio de esta ciudad a Don Alexandro Miller, vecino de Santiago de Chile", en ARAR, Protocolos Notariales, Manuel Primo de Luque 724, fol. 767.

${ }^{38}$ Acerca de las más importantes casas extranjeras en Valparaíso durante estos años, véase el capítulo III del libro de Eduardo Cavieres Figueroa, Comercio chileno y comerciantes ingleses 1820-1880: un ciclo de historia económica, Valparaíso, Universidad Católica de Valparaíso, 1989, pp. 103-171.

39 “Aviso. La casa de los señores Wyllie, Miller y Compañía de esta ciudad, se nombra de la fecha en adelante Wyllie, Jack y Compañía bajo cuya firma le reconocerán las personas que tengan créditos en ella", Periódico El Republicano, tomo 7, № 39, Arequipa, 29 de septiembre de 1829.

40 "Los señores Wyllie, Jack y Compañía representados por Juan C. Jack del comercio de esta ciudad protestaban ser nula y de ningún valor la escritura pública que en 23 de junio del presente año otorgaron los señores Wyllie, Miller y Compañía a su nombre en la ciudad de Santiago de Chile", en ARAR, Protocolos Notariales, Matías Morales 756, fol. 165.

${ }^{41}$ Witt, op. cit., vol. I, pp. 61-62.

42 "Aviso de comercio. Todos los individuos que tengan asuntos con la casa que giraba bajo la firma de Wyllie, Jack y Compañía que queda disuelta se entenderán desde esta fecha en que corre bajo su nombre Juan C. Jack". Periódico El Republicano, tomo 10, № 26, Arequipa, 26 de julio de 1835.

${ }^{43}$ John Mills et al., Rosehaugh. A house of its time, Inverness-Scotland, Avoch Heritage Association Rosehaugh, 1997, p. 23.

${ }^{44}$ Heinrich Witt, Diario 1824-1890. Un testimonio personal sobre el Perú del siglo XIX, Lima, Banco Mercantil, 1992, vol. II, p. 121. 
establecimiento comercial nada menos que en la capital del Perú, Lima, cosa que nunca ocurrió. ${ }^{45}$ Con respecto a la situación de predominio alcanzada por la mencionada compañía, el siguiente cuadro nos da una idea de ello.

CuAdro $\mathrm{N}^{\mathrm{o}} 2$

Derechos pagados en la aduana de Islay, 1836-1838

(en pesos)

\begin{tabular}{|l|r|r|r|r|}
\hline \multicolumn{1}{|c|}{ Casa de Comercio } & $\mathbf{1 8 3 6}$ & $\mathbf{1 8 3 7}$ & $\mathbf{1 8 3 8}$ & \multicolumn{1}{c|}{$\mathbf{1 8 3 9}$} \\
\hline Jack, Hermanos y Compañía & 12257 & 33607 & 34467 & 27227 \\
\hline Tayleur, Mac-Laughlin y Compañía & 6836 & 18203 & 17060 & 9444 \\
\hline Juan Moens & 3165 & 10833 & 8817 & 14462 \\
\hline Gibbs, Crawley y Compañía & 5970 & 7943 & 11716 & 10929 \\
\hline Santiago Le Bris / Andres Viollier & 7761 & 4844 & 19262 & 6440 \\
\hline Cristóbal Guillermo Schütte y Compañía & 1000 & 6599 & 11268 & 3179 \\
\hline José Marcó del Pont (argentino) & 2503 & 2968 & 6959 & 2843 \\
\hline Dickson, Price y Compañía & 816 & 1167 & 4407 & 5908 \\
\hline
\end{tabular}

Fuente: ARAR, Libros de la Tesorería de Arequipa, años 1836, 1837, 1838 y 1839.

Posicionada la casa en una situación dominante dentro de la región, en 1845 Santiago Jack decidió regresar a Inglaterra ${ }^{46}$ para hacerse cargo de la dirección de la casa matriz en Liverpool, luego del retiro de la sociedad de Juan ${ }^{47}$, pero antes entregó la administración del negocio en Arequipa al menor de sus hermanos, Carlos de veintiocho $a_{n ̃ o s}^{48}$, quien, pese a su juventud, se había venido ejercitando en el mundo de los negocios durante años, tanto en Liverpool ${ }^{49}$, junto a Juan, como en Arequipa a partir de 1838 , al lado de Santiago ${ }^{50}$. Con respecto a las habilidades del menor de los Jack, Santiago diría muchos años después que fue siempre "el más capaz de los tres" ${ }^{51}$. En tanto Heinrich Witt, afirmaba por aquella época y de manera similar, que Carlos como nuevo jefe de la casa "estaba en camino de adquirir una mayor fortuna" ${ }^{52}$. No era para menos, este joven empresario mantuvo su negociación a la vanguardia del comercio regional, sobre firmas

${ }^{45}$ Witt, op. cit., vol. II, pp. 215, 254 y 391.

${ }^{46}$ En su visita realizada a Escocia Santiago donó numerosos objetos traídos desde el Perú al museo de su natal Elgin como, por ejemplo: " 12 aves peruanas, 2 figuras vestidas, 6 especies diferentes de oro, 2 platos de cerámica, 2 conchas de nuez talladas, 2 arcos y 22 flechas y la figura momificada de una mujer”. Mills, op. cit., pp. 23-26.

47 “Aviso. Se da por la presente que la asociación que subsiste entre nosotros los bajo firmantes, como comerciantes de la Comisión, en Arequipa, en la República del Perú, bajo la firma de Jack, Hermanos y Compañía, se disuelve por consentimiento mutuo, en lo que respecta al subscrito John Charles Jack, que se retira de ella", The London Gazette, London, 1848, p. 59.

48 "Poder General. Don Santiago Jack vecino y del comercio a Don Carlos Jack, su hermano de esta vecindad para que perciba, demande y cobre", en ARAR, Protocolos Notariales, José María Chávez 584, fol. 827.

${ }^{49}$ Mills, op. cit., p. 23.

50 "Enterado por Don Carlos Jack a nombre de los señores Jack Hermanos y Compañía para que se abonen por la Aduana principal de Islay a cuenta de los derechos de internación o extracción que adeuden", en ARAR, Tesorería de Arequipa, Libro Manual 52, 17 de enero de 1838.

${ }^{51}$ Mills, op. cit., p. 27.

${ }^{52}$ Witt, op. cit., vol. II, p.165. 
como: Gibbs, Mac Laughlin, Schütte, Harmsen o Viollier, sino que, además, en 1852 abrió una sucursal en la ciudad de Tacna ${ }^{53}$, que por aquella época tenía una importante colonia británica y era el otro gran foco del comercio europeo en el sur del Perú, gracias a sus vinculaciones con el puerto de Arica y la república de Bolivia ${ }^{54}$.

Un hecho lamentable para el futuro de la casa arequipeña, fue la muerte intempestiva de Carlos Jack en abril de 1853, cuando se dirigía al puerto de Islay, al parecer, debido al agotamiento de la travesía, pues según Heinrich Witt, el joven Jack "se sentía orgulloso de realizar (este viaje) en un tiempo peligrosamente corto" ${ }^{55}$. Así, la administración, aunque provisional de la firma recayó en Guillermo Macandrew, escocés natural de Elgin, apoderado y futuro socio de la empresa, quien se desempeñaba hasta entonces como administrador de la sucursal en Tacna ${ }^{56}$. Un año después, llegó como jefe de Jack Hermanos y Compañía en el Perú, Carlos Church, cuñado de Juan Jack y socio principal de la empresa ${ }^{57}$. En 1858, Guillermo Macandrew abandonó la sociedad para instalarse en Valparaíso, mientras que Carlos Church se mantuvo al frente de ella hasta 1862, cuando la empresa cambió de denominación, llamándose Santiago Fletcher y Compañía, tanto en Inglaterra como en el Perú ${ }^{58}$.

53 "Don Carlos Jack como representante de la casa de comercio de los señores Jack, Hermanos y Compañía a Don Guillermo Macandrew para manejar su establecimiento mercantil que dichos señores van a abrir", en ARAR, Protocolos Notariales, Isidoro Cárdenas 557, fol. 61. "Poder especial por parte de Guillermo Macandrew a favor de Luis Stevenson", Archivo Nacional Histórico (Chile), Archivo Notarial de Arica, legajo 130, folios 606-610. Se agradece al historiador Jaime Rosenblitt, haber proporcionado este valioso material.

${ }^{54}$ Tan temprano como 1825, un viajero inglés señalaba: "Tacna parece más una colonia británica que una española. Es asombroso lo rápido que cada mercado abierto a nuestro comercio se ve saturado; es algo lamentable encontrar a nuestros nacionales compitiendo entre sí, los comerciantes y manufactureros comiéndose unos a los otros". Jorge Ortiz Sotelo, Perú y Gran Bretaña: política y economía (1808-1839), a través de los informes navales británicos, Lima, Asociación de Historia Marítima y Naval IberoamericanaInstituto de Estudios Internacionales-Pontificia Universidad Católica del Perú, 2005, pp. 101-102. Acerca del comercio de la ciudad de Tacna y su puerto Arica, durante la primera mitad del siglo XIX, véase, Jaime Rosenblitt, "El comercio tacneño-ariqueño durante la primera década de vida republicana en el Perú, 18241836", en Historia, vol. 43, N 1, Santiago, 2010, pp. 79-112; Jaime Rosenblitt B., Centralidad geográfica, marginalidad política: La región Tacna-Arica y su comercio, 1778-1841, tesis de para optar al grado de Doctor, Santiago, Pontificia Universidad Católica de Chile, 2011; Jaime Rosenblitt B., "De arrieros a mercaderes. Orígenes de los comerciantes de la región Tacna-Arica, 1776-1794”, en Revista de Indias, vol. LXxiv, N 260, Madrid, 2014, pp. 35-66 y Jaime Rosenblitt B., "Los negocios de la casa Hainsworth y Compañía en Tacna y Arica, 1841-1868. Una mirada al comercio regional”, en América Latina en la Historia Económica, vol. 24, №3, México, 2017, pp. 41-70.

55 "Poder. Don Thomas Crompton residente y vecino del puerto de Islay, vicecónsul de su Majestad Británica en la ciudad a Don Guillermo Macandrew del comercio de esta ciudad”, en ARAR, Protocolos Notariales, Juan Nepomuceno Pastor 774, fol. 686. Asimismo, véase Witt, op. cit., vol. II, p. 165 y Mills, op. cit., p. 27.

56 "Poder. Don Guillermo Macandrew vecino y del comercio a su señor padre Don Guillermo Duncan Macandrew, residente en el puerto de Liverpool en la Gran Bretaña”, en ARAR, Protocolos Notariales, Isidoro Cárdenas 557, fol. 379.

${ }^{57}$ En 1838, Juan se casó con la señorita Elizabeth Church. Mills, op. cit., p. 23. "Aviso. La casa mercantil que gira en esta plaza bajo la razón social de Jack Hermanos y Compañía que ha corrido a cargo del socio Don Guillermo Macandrew desde principios del año 1853, por ausencia temporal de este, desde hoy corre a cargo del socio Don Carlos Church", periódico El Republicano, tomo 28, № 26, Arequipa, 7 de abril de 1855.

${ }^{58}$ Desde octubre de 1855 Juan y Santiago Jack habían cambiado su apellido por Fletcher, cumpliendo la última voluntad de la madre (Isabel Fletcher) antes de morir, a principios de ese año. Mills, op. cit., p. 29. "Agregación de poder. Don Carlos Church, casado, comerciante mayor de 30 años, socio representante de la casa de comercio que hoy gira en esta ciudad bajo la razón social 'Santiago Fletcher y Compañía', que antes 
Bajo la nueva denominación, dicha casa de comercio continuó sus actividades de importación y exportación -la de Tacna, al parecer, fue cerrada en 1863- aunque su liderazgo en la región venía siendo disputado desde hacía muchos años por otras casas como: Gibbs y Compañía, Braillard Hermanos, Jerónimo Guillermo Harmsen, Jorge Stafford, entre otras. A lo largo de este último periodo, la negociación en Arequipa corrió bajo la dirección de un nuevo socio Santiago $\operatorname{Ryder}^{59}$ y a partir de 1869, de un antiguo empleado, Guillermo Ricketts ${ }^{60}$. Ese mismo año, Carlos Church renunció a la sociedad y se retiró de la actividad comercial ${ }^{61}$. En 1874 fue incorporado Guillermo Enrique Fletcher, sobrino de Santiago y la compañía cambió otra vez de referencia a Fletcher, Ryder y Compañía ${ }^{62}$. El fin de la antigua Casa Jack llegó con el inicio de la Guerra del Pacífico (1879-1883), que enfrentó durante cuatro años a Chile y Perú, cuando en medio de la conflagración Santiago Fletcher (antes Santiago Jack), socio principal de ella, transfirió la propiedad de la empresa a José V. Rivera, empleado de la casa desde hacía muchos años ${ }^{63}$.

\section{ACTIVIDADES COMERCIALES}

Dependiendo de diferentes factores, los comerciantes extranjeros avecindados en Arequipa en la primera mitad del siglo XIX, se involucraron en actividades tan diversas como la importación y comercialización de mercancías, exportación de materias primas y metales preciosos, compra de propiedades urbanas y rurales, habilitación minera y, en menor medida, la explotación de algún yacimiento, de forma individual o asociados con otros empresarios. En el caso particular de los hermanos Jack y sus consocios o representantes, en el casi medio siglo de ejercicio profesional las actividades giraron en torno a la importación y comercialización de efectos de Europa, la exportación de materias primas y metales preciosos y como complemento de ellas, la adquisición de varias re-

\footnotetext{
ha girado por largo tiempo bajo la denominación o razón social Jack Hermanos y Compañía”, en ARAR, Protocolos Notariales, Isidoro Cárdenas 562, fol. 34.

59 "Don Santiago Ryder, socio representante y actual jefe de la casa de comercio Santiago Fletcher y Compañía, confiero poder amplio y general a Don Alejandro Sandison”, en ARAR, Protocolos Notariales, Isidoro Cárdenas 562, fol. 115.

60 "Don Santiago Ryder, comerciante de esta vecindad, socio y jefe representante de la casa de comercio de Santiago Fletcher y Compañía, único que reside en esta ciudad, confiere el siguiente poder a Don Guillermo Ricketts", en ARAR, Protocolos Notariales, Isidoro Cárdenas 566, fol. 41.

61 "Aviso. Se da por la presente que la Asociación que hasta ahora subsistía entre nosotros los abajo firmantes, que realiza negocios en Liverpool, en Inglaterra, y en Arequipa, en Perú, como Comerciantes, bajo la firma de James Fletcher and Company, ha sido disuelta hoy por mutuo consentimiento, en lo que respecta al infrascrito Charles Church, que se retira del trabajo. Liverpool, 31 de diciembre de 1869", The London Gazette, London, 1869, p. 7483.

62 "Aviso. Se da por la presente que la Asociación que hasta ahora subsiste entre los abajo firmantes, como Comerciantes; en Liverpool, en Inglaterra, y en Arequipa, en Perú, bajo la firma de James Fletcher and Co., este día se disuelve por consentimiento mutuo. Todas las deudas para y por la empresa serán recibidas y pagadas por el suscrito, James Ryder y William Henry Fletcher. Fechado el 31 de diciembre de 1873. James Fletcher, James Ryder, William Henry Fletcher", The London Gazette, London, 1874, p. 21.

${ }^{63}$ Mills, op. cit., p. 39.
} 
cuas de mulas para asegurar el necesario transporte ${ }^{64}$. En menor medida, se comprometieron con la compra de propiedades urbanas o rurales, salvo que ella haya sido producto del embargo a causa de alguna deuda impaga y mucho menos, la explotación minera, considerada por aquella época como una actividad de alto riesgo ${ }^{65}$.

\section{LAS IMPORTACIONES}

La ausencia de una verdadera industria peruana, la expansión de la producción industrial europea, la creciente demanda por productos extranjeros, los bajos precios de ellas y el deseo de hacer grandes fortunas en muchos comerciantes, favorecieron la importación de toda clase de mercancías hacia la región; mercancías como: tejidos de diversas clases, licores, alimentos en conserva, papel, libros, hierro, muebles, vajilla, mercurio, herramientas, máquinas y hasta, armas. Desde este punto de vista, los géneros importados por la Casa Jack no se diferenciaban a los de otras casas comerciales establecidas en la localidad, salvo por las cantidades o volúmenes recibidos, en los que superaban a la mayor parte de sus colegas y desde épocas muy tempranas. Así se puede comprobar en un informe de la Aduana de Arequipa correspondiente solo al mes de setiembre de 1828 .

\section{CUADRO N $\mathrm{N}^{\circ} 3$}

Razón principal de los cargamentos marítimos recibidos por Juan Jack

\begin{tabular}{|c|c|}
\hline Bultos & Contenido \\
\hline 248 & 37200 libras de añil \\
\hline 51 & 106 resmas de papel genovés \\
\hline 21 & 36 quintales de hilos de cartas \\
\hline 14 & 24 quintales de acarreto \\
\hline 14 & 320 yardas de jergón \\
\hline 1 & 99 docenas de mechas \\
\hline
\end{tabular}

Fuente: El Republicano, tomo 3, No 39, Arequipa, 27 de septiembre de 1828 .

La mayor parte de estas mercancías las obtenían de los numerosos buques ingleses procedentes del puerto de Liverpool ${ }^{66}$, en menor medida de Valparaíso, donde la firma

\footnotetext{
64 "Venta de mulas. Don Mariano Obando Cárdenas, labrador y arriero vecino de Tiabaya y el señor Don Santiago Ryder, socio y jefe representante de la casa de comercio de los señores Santiago Fletcher de esta ciudad", en ARAR, Protocolos Notariales, Isidoro Cárdenas 564, fol. 51.

${ }^{65}$ Los primeros proyectos mineros en la región de Arequipa, emprendidos con capitales extranjeros después de la independencia, terminaron en sonoros fracasos, tanto por causas externas, relacionadas a la crisis del mercado londinense y el desconocimiento de la realidad americana, como por factores internos, además de la falta de insumos, trabajadores y el anegamiento de los socavones. Para más detalle, Víctor Condori, "Minería y empresa en Arequipa. Las minas de Caylloma durante el siglo xIx", en Revista de Investigación, vol. 7, Arequipa, 2016, pp. 31-50.

${ }^{66}$ Según John Wibel, durante esta época la mayor parte de comerciantes extranjeros, "generalmente vendían mercaderías en comisión antes de invertir su propio capital”. Wibel, op. cit., p. 369.
} 
Jack tenía su oficina principal desde 1836, bajo la dirección del mayor de los hermanos, Juan; quien estuvo encargado de recibir las materias primas y valores enviados desde el Perú y remitir las más surtidas mercancías comisionadas a su nombre por distintos productores ingleses ${ }^{67}$. En ese sentido, la casa de Arequipa aceptaba con frecuencia mercancías europeas a través del puerto de Islay, procedentes de varios barcos y en diferentes montos, a lo largo de todos los meses del año ${ }^{68}$.

El progresivo crecimiento de la Casa Jack en los negocios se expresó de manera evidente a través de los pagos realizados a la aduana de Islay, cuyo impuesto por concepto de importaciones fue mantenido por los distintos gobiernos de turno alrededor del $30 \%$ sobre el valor de los productos; y si a ello se suman los aportes realizados en razón de sus exportaciones, lo que se tendría es una cifra nada despreciable, que con el tiempo devino en la principal fuente de ingresos para las siempre exhaustas arcas del departamento ${ }^{69}$. Ahora, dependiendo de la época y de la vitalidad de otras actividades económicas como la minería o la viticultura, este porcentaje podía convertirse en más que esencial, como ocurrió en 1847 cuando los aportes solo de los comerciantes extranjeros, en impuestos y préstamos, significaron nada menos que el $61 \%$ del volumen recaudado por el tesoro local ${ }^{70}$. De la misma forma, los desembolsos de la Casa Jack, dependiendo de la coyuntura política que se vivía en el Perú durante las décadas de 1830 y 1840, llegaron a simbolizar entre el $15 \%$ y $30 \%$ de los ingresos anuales de la aduana principal de Islay, que en promedio bordeaban los ciento noventa mil pesos ${ }^{71}$. Así se puede comprobar en el siguiente cuadro, elaborado a partir de los derechos de importación y exportación pagados por la firma en la mencionada aduana.

\section{Cuadro $\mathrm{N}^{\circ} 4$}

Derechos pagados en la Aduana de Islay

por la Casa Jack Hermanos, 1837-1850 (en pesos)

\begin{tabular}{|c|c|c|c|}
\hline Año & Monto & Año & Monto \\
\hline 1837 & 33607 & 1844 & 48064 \\
\hline 1838 & 37467 & 1845 & 19372 \\
\hline 1839 & 29794 & 1846 & $4523^{* *}$ \\
\hline
\end{tabular}

${ }^{67}$ Mills, op. cit., p. 23.

${ }^{68}$ Periódico El Republicano, tomo 12, $\mathrm{N}^{\mathrm{os}_{\mathrm{s}}} 4,9,17,24,32,37,43$ y 62, Arequipa, 1837; tomo $13, \mathrm{~N}^{\mathrm{os}_{\mathrm{s}}} 6$, 18, 20, 34, 38, 55 y 63, Arequipa, 1838.

${ }^{69}$ Con el inicio de la república la región experimentó una depresión económica en comparación a los últimos años de gobierno colonial, tan crítica situación se manifestó en los ingresos de la tesorería de Arequipa durante la primera mitad del siglo XIX. Así en 1824 esta alcanzó 1134515 pesos; en 1830, 830421; en 1840, 364434 y en 1850, 322556 pesos. ARAR, Tesorería de Arequipa, años 1822-1827 y Betford Betalleluz, Población y fiscalidad en Arequipa a inicios de la República, tesis de Magíster, Lima, Pontificia Universidad Católica del Perú, 2014, pp. 119-128.

${ }^{70}$ Ese año los ingresos del tesoro alcanzaron un poco más de 466000 pesos, los ingresos de aduanas, 190000 y los empréstitos de los comerciantes, cerca de 77000 pesos. Betalleluz, op. cit., pp. 28-31.

${ }^{71}$ Aunque no se cuenta con datos globales para todos los años, en 1846 la Aduana de Islay recaudó 192459 pesos; en 1847, 190574 pesos; en 1848, 142989 pesos; en 1849, 163496; en 1850, 161468 pesos; en 1852, 238190 pesos y en 1853, 269622 pesos. ARAR, Tesorería de Arequipa, años 1846-1853. 


\begin{tabular}{|l|l|l|l|}
\hline 1840 & 53244 & 1847 & 37465 \\
\hline 1841 & 50483 & 1848 & 37184 \\
\hline 1842 & 36521 & 1849 & 65303 \\
\hline 1843 & $73477^{*}$ & 1850 & 47676 \\
\hline
\end{tabular}

"Incluye algunos préstamos al gobierno. ${ }^{* *}$ Solo se registraron cinco meses de ese año. Fuente: ARAR, Tesorería de Arequipa, años 1837-1850.

\section{LA COMERCIALIZACIÓN}

En Arequipa existían cientos de personas dedicadas al comercio durante esta época, pero muy pocas de ellas fueron identificadas bajo la categoría de grandes importadores o almaceneros, dentro de ese selecto grupo se encontraba Jack Hermanos ${ }^{72}$. A partir de las regulaciones gubernamentales, los Jack expendían sus efectos al por mayor a medianos comerciantes y tenderos de la ciudad y sus alrededores ${ }^{73}$, también a aquellos provenientes de las provincias del interior como: Camaná, Condesuyos, Caylloma y la Unión ${ }^{74}$; de algunos departamentos cercanos como: Cuzco, Puno, Moquegua y Ayacucho $^{75}$ e, incluso, de regiones más alejadas como La Paz en Bolivia ${ }^{76}$. Las ventas se realizaban al crédito, con un interés de $1 / 2 \%$ al mes y por plazos comprendidos entre dos y cuatro meses como máximo ${ }^{77}$, previa garantía de un aval, una propiedad o las correspondientes mercancías adquiridas ${ }^{78}$. Con respecto a las cantidades entregadas, estas dependían tanto de la capacidad de pago del comprador como del lugar de residencia de los susodichos, vale decir, los comerciantes de la ciudad recibían casi siempre mayores montos que aquellos avecindados fuera de ella ${ }^{79}$. Una de las razones, además de la con-

72 Según el censo de población y de ocupaciones de 1847, en la ciudad de Arequipa había 554 personas dedicadas al comercio, de ellos, cinco estaban registrados como almaceneros, 362 como comerciantes y 187 como tenderos. Periódico El Republicano, tomo 21, № 36, Arequipa, 23 de mayo de 1847.

73 "Obligación. Don Pedro José Gamio vecino y del comercio a Don Juan Jack del comercio de esta ciudad la cantidad de 26.446 pesos", en ARAR, Protocolos Notariales, Matías Morales 750, fol. 422. "Obligación. Don José Hurtado y Villafuerte vecino, le ha comprado a Don Juan Jack de este comercio 500 pesos en efectos de Europa, bayetas de pellón, por 4 meses", en ARAR, Protocolos Notariales, Calixto Villanueva 892 , fol. 510

74 "Don Guillermo Macandrew a Don Saturnino Cornejo para que pueda en el viaje que va emprender a Chuquibamba, Majes, Cotahuasi y la Unión cobrar las cantidades que al presente están debiendo varias personas en los lugares indicados",en ARAR, Protocolos Notariales, Isidoro Cárdenas 557, fol. 364.

${ }^{75}$ ARAR, Protocolos Notariales, Manuel Primo de Luque 725, fol. 557; ARAR, Protocolos Notariales, Isidoro Cárdenas 558, fol. 88 y 560, fol. 102.

76 "Poder. Los señores Wyllie Jack y Compañía de la casa de Arequipa entregan su poder cumplido a los señores Eguren Mendoza y Compañía de la casa de la ciudad de La Paz para que cobre y pueda cobrar", en ARAR, Protocolos Notariales, Matías Morales 756, fol. 227.

${ }^{77}$ ARAR, Protocolos Notariales, Matías Morales 756, fol. 71; 753, fol. 160 y en ARAR, Protocolos Notariales, Casimiro Salazar 834, 14 de abril de 1835.

${ }^{78}$ ARAR, Protocolos Notariales, Matías Morales 753, folios 166 y 185.

${ }^{79}$ Entre los principales deudores a la Casa Jack, estuvieron los mencionados: Pedro José Gamio (26446 pesos), José Anselmo Bustamante (16120 pesos), Juan de Dios Medina (12.030 pesos) y Fabián Fernández (8.422 pesos), todos vecinos y del comercio de la ciudad. Mientras que: Saturnino Gamio del Cusco debía 4755 pesos), Marcos Vargas también del Cuzco, 1951 pesos; Manuel Valdivia de Chuquibamba, 1744 pesos; Juan Martín de Larrañaga de Camaná, 800 pesos y Francisco Julián Pérez de Majes, 689 pesos. 
fianza, pudo haber estado relacionada con la facilidad y cercanía para realizar los cobros o la rapidez a la hora de solicitar la intervención de las autoridades judiciales y de comercio, en caso de presentarse moras, quiebra o iliquidez de los antes mencionados ${ }^{80}$.

Durante estos años, el hacer efectivas las deudas, impagas o retrasadas, fue siempre una tarea complicada para los acreedores, debido a factores como la inestabilidad política, los cambios permanentes de autoridades, la fuga o muerte de los deudores y hasta, la poco desarrollada cultura de pago de ciertos individuos. Si a todo ello se le suman los estrechos márgenes de ventas, ganancias e inversiones de los acreedores, se tendrá como resultado la multiplicación de demandas ante las autoridades judiciales, en una época donde aún estaba pendiente la redacción de una legislación actualizada que normara sobre estos casos y en su ausencia se apelaba a los reglamentos coloniales, como la Novísima Recopilación de Leyes (1805) o las Ordenanzas de Bilbao (1737). Las cosas se complicaban aún más si el deudor residía en una provincia alejada, donde era muy difícil solicitar la intervención de las autoridades políticas o militares. Frente a esta realidad poco esperanzadora, algunos comerciantes extranjeros con mayores volúmenes de mercancías y créditos, como los Jack, buscaron solucionar el problema directamente mediante diversos procedimientos. En primer término, se buscó la conciliación o arreglo amistoso con los deudores, refinanciando la deuda, condonando los intereses, otorgando nuevos plazos de pago e, incluso, proporcionando pequeñas cantidades de mercancías a crédito a fin de que no se paralicen sus actividades y continúen con los pagos ${ }^{81}$. El objetivo de todo ello buscaba evitar los procesos judiciales, que eran largos y costosos y muchas veces, terminaban beneficiando al deudor ${ }^{82}$. Una práctica recurrente de los Jack buscó la cancelación de los créditos atrasados a través de la entrega de pequeñas cantidades en dinero de forma semanal o mensual hasta su extinción definitiva, lo cual permitía asegurar la devolución, por lo menos, de una parte del monto principal ${ }^{83}$. Ahora, cuando el insolvente o moroso residía en una provincia alejada, se otorgaban poderes a conocidos viajeros o comerciantes instalados en aquella región. En ciertas ocasiones, cuando algún comerciante tenía deudas no con uno sino con varios proveedores o alma-

80 "Poder. Don Carlos Jack de la casa Jack Hermanos y otros a Don Bernardo Neyra de esta vecindad", en ARAR, Protocolos Notariales, Juan José Salazar 846, fol. 185.

81 "Los señores Jack y Compañía a fin de facilitarle y hacerle menos pesada la satisfacción o mejorar en parte su situación, se obligan a proporcionarle los efectos que necesite su almacén a los precios en que convinieren y en cantidades que les necesite su almacén a los precios en que convinieren y en cantidades que les parezca a dichos señores", ARAR, Protocolos Notariales, Manuel A. Zegarra 915, fol. 472. Además, ARAR, Protocolos Notariales, Matías Morales 756, fol. 70 y Toribio Linares 710, fol. 3.

${ }^{82}$ El comerciante inglés Samuel Haigh, decía al respecto, "Los principales compradores eran unos cincuenta tenderos que vivían simplemente de manos a boca; de modo que, si no podían revender lo que compraban, no eran bastante honrados para pagar las cuentas al vencimiento, el vendedor se veía precisado a esperar su comodidad; no había nada parecido a leyes de quiebra. El único remedio para el acreedor era trabar embargo en la tienda, lo que es a menudo un estorbo puesto en el camino, pues impide que el deudor venda nada. El juez de comercio casi siempre se inclina al lado del tendero, lo que está en su propio interés". Haigh, op. cit., p. 24.

83 "Obligación. Don Juan Pío Tirado vecino y del comercio de esta ciudad a Don Juan Jack del comercio de esta, 1.993 pesos de varios efectos que le compró y cuyos plazos se hallan cumplidos a 200 pesos mensuales", ARAR, Protocolos Notariales, Matías Morales 752, fol. 61; Manuel Primo de Luque 725, fol. 648 y Mariano Prieto 799, fol. 125. 
ceneros de la ciudad, los acreedores unían sus esfuerzos con el único objetivo de lograr la recuperación de sus préstamos, entregando poderes generales a un representante en común ${ }^{84}$. El uso de la justicia, encabezada por el juez de comercio, casi siempre se realizaba en última instancia $\mathrm{y}$, por lo general, terminaba con el embargo de alguna propiedad, sea esta un cuarto, una casa, chacra, hacienda o las mismas mercancías entregadas ${ }^{85}$; en caso de tratarse de una propiedad inmueble, se tasaba y luego vendía al mejor postor (casi siempre otro comerciante) y el monto de lo obtenido se repartía, sobre la base de los créditos proporcionados ${ }^{86}$. A lo largo de este periodo, se encontraron contados casos de venta o compra de deudas impagas de parte de un comerciante o casa comercial, a diferencia de otras regiones como, por ejemplo, Tacna ${ }^{87}$.

\section{LAS EXPORTACIONES}

Según su naturaleza, los productos exportados estuvieron divididos en dos rubros: metales preciosos y materias primas. El primero de ellos, vale decir, la extracción de metales preciosos con rumbo a Europa, en forma de plata piña y chafalonía, oro en polvo, pasta y en moneda corriente, significaron para los Jack un complemento de sus actividades de importación y comercialización de efectos y por el volumen que estas exportaciones alcanzaron, se puede afirmar que las actividades de la Casa durante esta época fueron bastante lucrativas como muy pocas establecidas en la región. Valdría bien contextualizar ese éxito para tener una idea de la real dimensión de sus negocios.

Como se sabe, desde el siglo Xvi las principales fuentes de metales preciosos y, por tanto, de capital circulante, fueron las minas del Perú y el Alto Perú, ahora convertida en

84 “Obligación, ajuste y convenio. Don Patricio Muñoz vecino y del comercio de esta ciudad, siendo deudor su hijo Don Bartolomé Muñoz de los señores Don Samuel Went, representante de la casa Gibbs Crawley y Compañía, Don Diego Kendall representante de Thomas Mac Laughlin, Guillermo Harmsen, Luis Braillard representante de Juan Andrés Viollier y Compañía, Cristóbal Guillermo Schütte y Compañía, Carlos Jack de Jack Hermanos y Compañía de la cantidad de 32.152 pesos", ARAR, Protocolos Notariales, Mariano Prieto 800, folios 15 y 31; Juan José Salazar 846, fol. 185.

85 “Cesión y traspaso. Don Jerónimo Guillermo Harmsen, Don Cristóbal Guillermo Schütte, Don Carlos Eduardo Stubbs, Don Carlos Jack, Don Diego Kendall y de la otra Don Manuel García vecino y del comercio de esta ciudad", ARAR, Protocolos Notariales, Juan Nepomuceno Pastor 771, fol. 203.

86 "Venta de casa. Los señores Don Eduardo Stubbs, como representante de la casa Gibbs, Don Diego Kendall de Thomas Mac Laughlin, Don Carlos Jack de Jack Hermanos y Compañía, Don Guillermo Harmsen, Don Fernando Leplatenier por la de Cristóbal Guillermo Schütte y Compañía y Don Luis Braillard, representante de la de Andrés Viollier... han determinado venderla a la señora Doña María Dolores Averásturi esposa legítima de Don Guillermo Harmsen en la cantidad líquida de 2.101 pesos, cuya cantidad ha sido distribuida entre los mencionados comerciantes", en ARAR, Protocolos Notariales, Mariano Prieto 803, fol. 401.

${ }^{87}$ Uno de los pocos casos conocidos se produjo en diciembre de 1827, cuando Francisco de los Heros del comercio de Arequipa, a nombre de Lucas de la Cotera cedía a favor de la Casa Le Bris-Bertheaume todos los créditos activos "con autorización bastante de este y con la rebaja de un $25 \%$ " que en documentos, conciliaciones y letras ascendían a la suma de 127085 pesos, "siendo de cuenta de los compradores los resultados de las cobranzas". Condori, "El francés Santiago Le Bris...", op. cit., p. 273. Para el caso de la ciudad de Tacna, Jaime Rosenblitt estudia la Casa Hainsworth y Compañía, especializada en el negocio de compra de deudas a los comerciantes locales. Rosenblitt, "Los negocios de la casa Hainsworth...", op. cit., pp. 41-70. 
la República de Bolivia. Con la Independencia, muchas de estas minas quedaron paralizadas en su ya exigua producción y en Arequipa la producción de plata entró en una escala depresiva de la que solo escaparía a fines del siglo $\mathrm{XIX}^{88}$; en ese sentido, el aporte de la minería argentífera a la economía regional no fue capaz de satisfacer las necesidades del mercado local y menos aún del comercio de importaciones, obligando a sus grandes negociantes a la permanente búsqueda de nuevas fuentes de aprovisionamiento en las provincias y fuera del departamento.

Tomando como base los registros oficiales de exportación por el puerto de Islay, se consignan en el siguiente cuadro los volúmenes de metales preciosos que en sus diferentes formas eran enviados cada año por la Casa Jack con dirección al puerto de Liverpool. Estos datos corresponden a los años dorados de la mencionada Casa.

\section{CUADRO $\mathrm{N}^{\circ} 5$}

Exportaciones de metales preciosos de la Casa Jack, 1838-1851*

\begin{tabular}{|c|c|c|c|c|}
\hline Años & Plata piña (marcos) & Plata chafalonía (marcos) & Oro en pasta (onzas) & Pesos fuertes \\
\hline 1838 & - & 770 & 642 & 66860 \\
\hline 1839 & - & 644 & 200 & 50602 \\
\hline 1841 & $40000^{* *}$ & - & - & - \\
\hline 1843 & 14000 & - & - & - \\
\hline 1846 & 8521 & 1403 & 1683 & 4328 \\
\hline 1847 & 6856 & 949 & 1877 & 10939 \\
\hline 1848 & 13183 & 829 & 1799 & 6780 \\
\hline 1849 & 7794 & 1644 & 2289 & 2000 \\
\hline 1850 & 2986 & 1085 & 2438 & 5500 \\
\hline 1851 & 5205 & 519 & 1012 & 4550 \\
\hline
\end{tabular}

* Los derechos pagados por la extracción de metales preciosos eran: cuatro reales por cada marco de plata piña o chafalonía, dos reales por cada onza de oro y $5 \%$ sobre el total de pesos fuertes.

${ }^{* * *}$ En sociedad con el comerciante Samuel Went.

Fuente: ARAR, Tesorería de Arequipa 1838, 1839, 1843, 1848, 1849 y 1851. El Republicano, tomos 20, Arequipa, 1846; 21, Arequipa 1847; 22, Arequipa 1848; 23, Arequipa 1849; 24, Arequipa 1850 y 25, Arequipa 1851.

Aunque incompletos dichos datos tomados de fuente oficial, proporcionan valiosa información sobre la evolución de las exportaciones de la casa arequipeña desde fines de la década de 1830 hasta principios de 1850 . Así, se comprueba que hasta 1839 por lo menos, los mayores volúmenes extraídos correspondían a plata amonedada, en cambio, a partir de la década de 1840 , este lugar será ocupado por la plata piña ${ }^{89}$. Asimismo, gra-

${ }^{88}$ En 1820, la producción de plata de la intendencia había sido de 37405 marcos; en 1830 de 18422 y para 1835, de solo 3673 marcos anuales. José Deustua, La minería peruana y la iniciación de la República: 1820-1840, Lima, Instituto de Estudios Peruanos, 1986, pp. 247-259.

${ }^{89}$ Entre 1836 y 1841 funcionó en Arequipa una Casa de Moneda que pudo facilitar el acceso a ella por parte de los comerciantes, quienes depositaban la plata piña y recibían moneda fuerte y fraccionada. Sobre el tema véase el importante estudio de Horace P. Flatt, The coins of independent Peru. Volume IV: The Pasco and Arequipa Mints, Texas, Haja Enterprises Terrell, 1996, pp. 89-126. Por otro lado, en el primer semestre de 1841, Santiago Jack depositó en dicha Casa de Moneda 14288 marcos de plata en barras para su amonedación. ARAR, Casa de Moneda, Libro Mayor 66, Data, mayo-julio 1841. Asimismo, mucha de esta plata se obtenía a partir de las transacciones mercantiles realizadas con vecinos y comerciantes de diferentes 
cias a este mismo cuadro se advierten los enormes volúmenes de metales preciosos que extraían los Jack y compararlos con la producción departamental de algunos años antes (verbi gratia, en 1835 cuando alcanzó 3673 marcos) y sorprende aún más, tratándose de una sola casa comercial. Viendo las cifras de extracción de metales preciosos en forma conjunta, es decir, incluyendo a los principales comerciantes de la ciudad y tomando como base un solo año, estas parecen, incluso, más impresionantes. Por ejemplo, el año 1846 cuando se extrajeron por el puerto de Islay 22079 marcos de plata piña, 3301 marcos de plata chafalonía, 7473 onzas de oro en pasta y polvo, 1530 onzas de oro selladas y 133446 pesos en plata amonedada.

\section{CUADRO $\mathrm{N}^{\mathrm{o}} 6$}

\section{Extracción de metales preciosos por el puerto de Islay, 1846}

\begin{tabular}{|l|c|c|c|c|c|}
\hline \multicolumn{1}{|c|}{ Comerciante } & $\begin{array}{c}\text { Plata piña } \\
\text { (marcos) }\end{array}$ & $\begin{array}{c}\text { Plata chafalonía } \\
\text { (marcos) }\end{array}$ & $\begin{array}{c}\text { Oro en pasta y polvo } \\
\text { (onzas) }\end{array}$ & $\begin{array}{c}\text { Oro } \\
\text { sellado }\end{array}$ & Pesos fuertes \\
\hline Jack Hermanos & 8521 & 1403 & 1683 & & 4328 \\
\hline Gibbs Crawley & 7845 & 516 & 206 & 206 & 53683 \\
\hline $\begin{array}{l}\text { Thomas Mac } \\
\text { Laughlin }\end{array}$ & 242 & 42 & 3024 & & 22613 \\
\hline Andres Viollier & 1420 & 640 & 1189 & & 5809 \\
\hline Cristóbal G. Schütte & 323 & 21 & 203 & & 14626 \\
\hline Otros & 3728 & 1181 & 1168 & 1324 & 33387 \\
\hline Totales & $\mathbf{2 2 0 7 9}$ & $\mathbf{3 8 0 1}$ & $\mathbf{7 4 7 3}$ & $\mathbf{1 5 3 0}$ & $\mathbf{1 3 3 4 4 6}$ \\
\hline
\end{tabular}

Fuente: El Republicano, tomo 20, Arequipa, enero-diciembre de 1846.

Aquí se tiene la cara menos agraciada del comercio extranjero en Arequipa: la fuga de capitales y las pocas inversiones directas en la economía regional durante estos críti$\cos$ años ${ }^{90}$. A la larga, tal situación se convirtió en un motivo de queja permanente para los comerciantes y hacendados locales ante las autoridades regionales y nacionales; además de ser una de las causas de la animosidad existente contra los extranjeros y el origen de continuos pedidos para su expulsión definitiva del país ${ }^{91}$. No era para menos,

ciudades, pueblos y centros mineros de la región, además de los propios bancos de rescate, como ocurrió en febrero de 1841, cuando Santiago Jack compró al supremo gobierno cuatro barras de plata pertenecientes al Banco de Rescate de Puno, "por ser extraídas de esta casa (de Moneda) según orden de S. E. el Jefe Supremo Don Manuel Ignacio Vivanco", en ARAR, Casa de Moneda, Libro Manual 65, 6 de febrero de 1841.

${ }^{90}$ Desde antes de la independencia del Perú, las autoridades virreinales adoptaron una serie de medidas para evitar que en medio de la guerra drenaran grandes volúmenes de plata o moneda rumbo al extranjero, prohibiendo el comercio clandestino de la plata en pasta; confiscando las existentes en caso se pretendan utilizar en actividades de contrabando y hasta, trasladando la plata fundida a la Casa de la Moneda del Cuzco, última capital y sede del gobierno virreinal. "Superior orden del Excelentísimo Virrey concerniente a evitar el comercio clandestino de plata", en Archivo Municipal de Arequipa (AMA), Libro de Actas del Cabildo 29, 14 de junio de 1823. Asimismo, John Fisher, El Perú Borbónico 1750-1824, Lima, Instituto de Estudios Peruanos, 2000, p. 219 y Colección Documental de la Independencia del Perú, tomo xxII, vol. 3, decreto del Virrey de junio de 1824 , p. 40.

${ }^{91}$ La escasez de capital circulante en la región se agravaba aún más ante la negativa de tales monopolistas de proporcionar créditos a vecinos, artesanos, hacendados y comerciantes de la ciudad. En ese sentido, el rico propietario arequipeño Juan Mariano de Goyeneche y Barreda se constituyó en la principal fuente de 
en 1841 Santiago Jack en sociedad con el comerciante inglés Samuel Went, solicitó una licencia al prefecto del departamento para extraer nada menos que cuarenta mil marcos de plata piña por el puerto de Islay, mediante la entrega de diez mil pesos como adelanto por los derechos de exportación, licencia que fue aprobada poco después por el mismísimo presidente Agustín Gamarra ${ }^{92}$. Al respecto, el viajero francés Eugenio de Sartiges, a pesar de haber permanecido poco tiempo en el Perú, pudo advertir muy bien la naturaleza de este problema:

"Los americanos españoles tienen pocos productos indígenas que dar a cambio de las mercaderías de Europa y se ven forzados a pagarlas en dinero. Ese dinero una vez que está en la caja del negociante extranjero, infaliblemente se traslada a Europa. Por eso muchas veces se han presentado peticiones a las cámaras peruanas, tendientes a expulsar del país a los comerciantes extranjeros a fin de impedir esa exportación de divisas monetarias y el mismo pedido se renueva en cada conmoción política"93.

Afortunadamente, esta situación habría de cambiar algunas décadas después de la visita de Eugenio de Sartiges, por iniciativa de los propios comerciantes extranjeros, quienes comenzaron a inclinarse por algunos productos nativos de alta demanda en el mercado europeo, como la cascarilla y la lana de ovejas y camélidos ${ }^{94}$. Frente a aquellas nuevas fuentes de beneficio, la Casa Jack no se mantuvo al margen y desde fines de la década de 1830 la encontramos contratando o demandando a productores de las zonas altas del sur del Perú ${ }^{95}$ y remitiendo en persona o a través de agentes marítimos instalados en Islay, importantes cargamentos de lana hacia la casa matriz ubicada en Liverpool, para su posterior distribución a importantes fábricas de tejido inglesas ${ }^{96}$.

crédito y entre 1846-1852, otorgó préstamos en dinero contante y sonante por más de 104000 pesos a casi medio centenar de individuos de la localidad, en montos que oscilaban entre quinientos y veinte mil pesos, por el término de algunos meses y hasta dos años, cobrando un interés regular de $6 \%$ que en ocasiones llegaba hasta $12 \%$ anual. Existe copiosa información en ARAR, Protocolos Notariales, Casimiro Salazar 843 y 844 ; Santiago Hidalgo 638; Mariano García Calderón 599, 600 y 601; Isidoro Cárdenas 554 y 555 y Juan José Salazar 845,846 .

92 "Don Mariano Basilio de la Fuente a nombre del Estado y Don Samuel Went y Don Santiago Jack del comercio de esta ciudad...", en ARAR, Protocolos Notariales, José María Pastor 763, fol. 240.

${ }^{93}$ Eugenio de Sartiges, "Visita de Arequipa, 1834", en Estuardo Núñez (comp.), El Perú visto por viajeros, Lima, Ediciones PEISA, 1973, tomo I, p. 56.

${ }^{94}$ Aunque la cascarilla y las lanas ya eran exportadas a Europa desde fines del siglo XVIII, su crecimiento se produjo en el siglo XIX, aunque no de manera simultánea. Primero será la cascarilla y posteriormente las lanas. Heraclio Bonilla, Gran Bretaña y el Perú: Los mecanismos de un control económico, Lima, Instituto de Estudios Peruanos-Fondo del Libro del Banco Industrial del Perú, 1977, pp. 181 y 187.

95 “Poder General. El señor Don Santiago Jack natural de Escocia y vecino de esta ciudad de ejercicio comerciante a Don Francisco de los Heros para que cobre en la ciudad de Lima de Don Toribio Caraveda todas las lanas que con dinero del señor otorgante se compraron en el Cusco", en ARAR, Protocolos Notariales, José María Chávez 580, fol. 58. Asimismo, ARAR, Protocolos Notariales, Mariano Prieto 800, fol. 15; Isidoro Cárdenas 554, fol. 97; periódico El Republicano, tomo 20, № 28, Arequipa, 2 de mayo de 1846 y tomo 25, $\mathrm{N}^{\mathrm{o}}$ 40, Arequipa, 14 de junio de 1851.

${ }^{96}$ La fábrica de lana de Elgin en Escocia recibía con frecuencia fardos de lana fina provenientes del Perú a través de la Casa Jack Hermanos de Liverpool. Mills, op. cit., p. 27. Por ejemplo, en 1850, enviaron a Europa tres mil arrobas de lana de alpaca y al año siguiente, 17442 arrobas. Periódico El Republicano, tomos 24 y 25, Arequipa, 14 de septiembre y 30 de noviembre de 1850 . 


\section{CUADRo $\mathrm{N}^{\mathrm{0}} 7$}

Razón de los cargamentos de lana exportados por la Casa Jack, 1850-1851

\begin{tabular}{|l|c|c|}
\hline \multicolumn{1}{|c|}{ Fecha } & Lana de alpaca (libras) & Lana de oveja (libras) \\
\hline 14 setiembre 1850 & 37500 & - \\
\hline 30 noviembre 1850 & 37500 & 19000 \\
\hline 14 junio 1851 & 183750 & 11100 \\
\hline 22 octubre 1851 & 252300 & - \\
\hline
\end{tabular}

Fuente: El Republicano, tomos 24 y 25, op. cit.

\section{RELACIONES POLÍTICAS}

La permanencia prolongada de algunos comerciantes en el Perú no pudo preservarlos de los conflictos políticos que vivió este país durante sus primeros años denominados de iniciación de la República, caracterizados por las guerras nacionales, los levantamientos armados, las luchas caudillistas y los permanentes cambios en el gobierno. La forma como estos empresarios participaban era mediante la entrega de empréstitos pecuniarios, abastecimientos de mercancías, casi siempre tejidos, para la confección de uniformes y uno que otro donativo a la causa de algún caudillo. Aunque no estuvieron obligados a ello y sus bienes personales se encontraban protegidos por una flota de guerra con bandera inglesa o francesa fondeada en alguna estación de América del Sur, tampoco podían mantenerse indiferentes cuando las autoridades locales o nacionales solicitaban su diligente intervención a fin de atender las "urgentes necesidades del Estado". En primer lugar, porque era siempre favorable tener buenas relaciones con el poder de turno, no solo pensando en alguna dispensa en el futuro, sino, también, en caso de querer negociar un lucrativo contrato gubernamental con el objetivo de construir una obra pública o solicitar la consignación de guano para cualquier país de Europa ${ }^{97}$. En segundo término, porque muchos de los empréstitos eran devueltos con su respectivos intereses, en dinero efectivo o, sobre todo, a través de derechos de importación y exportación para toda clase de mercancías y a través de cualquier puerto de la República ${ }^{98}$.

A lo largo de su dilatada permanencia de casi medio siglo en la región, la relación de la Casa Jack con las autoridades políticas, aunque muy activa, se mantuvo siempre alrededor de los empréstitos y abastecimientos, a cualquier régimen que lo solicitase, pero nunca dentro de la militancia. En ese sentido, desde comienzos de su vida empre-

\footnotetext{
97 En 1848, el comerciante alemán Cristóbal Guillermo Schütte obtuvo un ventajoso contrato para construir una cañería de fierro y así abastecer con agua fresca el pueblo y los barcos anclados en el puerto de Islay, recibiendo una suma de 48000 pesos por el término de la obra. En 1861, este mismo comerciante en sociedad con su compatriota obtuvieron del gobierno de Castilla la consignación de guano para el mercado de Alemania y dos años después fue ampliado hacia los nuevos mercados de Suecia, Noruega, Dinamarca y el Imperio ruso. Víctor Condori, "Entre la crisis económica y la migración alemana. Las actividades del comerciante Cristóbal Guillermo Schutte en Arequipa, 1827-1850", en Jahrbuch für Geschichte Lateinamerikas, vol. 53, No 1, Colonia, 2016, pp. 143-184.

98 "Empréstitos. 5.000 pesos enterados a nombre del comerciante Don Juan Jack por empréstito al estado, reintegrable por la aduana de Arica, Islay e Iquique, Arequipa”, en ARAR, Tesorería de Arequipa, Libro Manual 43, 26 de septiembre de 1835.
} 
sarial Juan Jack contribuyó en distintos momentos con el tesoro local junto con otros colegas y a pedido de las autoridades de gobierno. Así, en enero de 1830, enteró tres mil pesos, por indicación del Prefecto del departamento y en noviembre de ese mismo año, mil doscientos pesos, para completar los ciento cincuenta mil exigidos por el general Agustín Gamarra, a fin de cubrir el pago de salarios de la división que debía embarcarse hacia el norte del país, escenario de la guerra entre Perú y la Gran Colombia en ese momento ${ }^{99}$. En adelante, las contribuciones pecuniarias continuaron de manera regular y con todos los bandos. Durante la Confederación Perú-Boliviana (1836-1839) a favor del gobierno protectoral ${ }^{100} \mathrm{y}$ al ser derrocado este, en beneficio de los restauradores ${ }^{101}$.

A causa de la situación de inestabilidad política interna y externa, las necesidades del ejército, puede entenderse, consumían una buena parte de los ingresos regulares del gobierno nacional, así como los del departamento de Arequipa; por ello, con frecuencia se buscaban empréstitos pecuniarios para cubrir sueldos, pensiones o su propia manutención y toda clase de tejidos para confeccionar los uniformes de los diferentes cuerpos que conformaban el Ejército del Sur. En este asunto, los llamados a contribuir eran los grandes almaceneros como la Casa Jack, porque solo ellos disponían de las cantidades y variedades que se solicitaban. El siguiente cuadro presenta algunas aportaciones de la Casa en beneficio del Ejército.

\section{CuAdro $\mathrm{N}^{\mathrm{o}} 8$}

\section{Relación de aportes de la Casa Jack al Ejército del Sur}

\begin{tabular}{|l|c|l|}
\hline \multicolumn{1}{|c|}{ Fecha } & Valor (pesos) & \multicolumn{1}{c|}{ Características } \\
\hline 19 febrero 1839 & 477 & $\begin{array}{l}\text { Por 212 yardas de paño azul entrefino que le han comprado al } \\
\text { precio de 18 reales la yarda. }\end{array}$ \\
\hline 19 julio 1841 & 6936 & $\begin{array}{l}\text { Abonados al comerciante don Santiago Jack por 2920 yardas de } \\
\text { paño que se le han comprado por el señor general de Ejército de } \\
\text { operaciones y prefecto del departamento don Ramón Castilla, } \\
\text { al precio de diecinueve reales la yarda para la construcción de } \\
\text { vestuarios de parada. }\end{array}$ \\
\hline 25 setiembre 1841 & 5372 & $\begin{array}{l}\text { Abonados al comerciante don Santiago Jack por 2202 yardas } \\
\text { de paño que se le han comprado al precio de diecinueve reales } \\
\text { yarda, por complemento de 4750 varas para mil quinientos } \\
\text { vestuarios de parada compuesto de: polaca, pantalón y botines, } \\
\text { sobre las 2306 varas siete ochavas que se entregaron en Puno. }\end{array}$ \\
\hline 23 marzo 1842 & 2429 & $\begin{array}{l}\text { Satisfechos al comerciante don Santiago Jack por 1262 yardas } \\
\text { de paño azul u otros colores a catorce reales yarda y 1 168 yar- } \\
\text { das de tocuyo inglés ancho. }\end{array}$ \\
\hline 8 marzo 1843 & 1096 & $\begin{array}{l}\text { Por el valor de 5371/2 yardas de paño de varios colores y 168 } \\
\text { yardas de tocuyo, para que se les abonen dicha cantidad por } \\
\text { derechos de internación o extracción que adeuden en la Aduana } \\
\text { Principal. }\end{array}$ \\
\hline
\end{tabular}

Fuente: Tesorería de Arequipa, años 1839, 1841, 1842 y 1843.

\footnotetext{
${ }^{99}$ ARAR, Tesorería de Arequipa, Libro Manual 25, 1 de enero y 3 de noviembre de 1828.

${ }^{100}$ ARAR, Tesorería de Arequipa, Libro Manual 45, 28 de abril de 1836.

${ }^{101}$ ARAR, Tesorería de Arequipa, Libro Manual 55, 15 de julio de 1839.
} 
No debería sorprender que ciertos empréstitos pecuniarios fueran otorgados más bien como adelantos a la Aduana de Islay por futuras operaciones mercantiles ${ }^{102}$, buscando, de este modo, asegurar la continuidad de sus actividades de importación y exportación de mercancías, ante cualquier cambio súbito de gobierno. Pero en caso de tratarse de un verdadero empréstito "desinteresado", obtenían la devolución del mismo, además, del pago de intereses que en aquella época llegaban al $2 \%$ mensual, mucho mayor al cobrado dentro del comercio local, que por lo general oscilaba entre $1 / 2 \%$ y $1 \%$ mensual ${ }^{103}$. Por otro lado, a través de los documentos oficiales se puede observar que muchos de los empréstitos enterados por la Casa Jack y por varios de sus colegas, fueron realizados tanto en dinero efectivo como en billetes del crédito nacional.

\section{CUADRO $\mathrm{N}^{\circ} 9$}

Razón de los empréstitos solicitados por el Prefecto a las casas extranjeras, 1839 (en pesos)

\begin{tabular}{|l|l|c|c|c|}
\hline \multicolumn{1}{|c|}{ Fecha } & \multicolumn{1}{c|}{ Comerciante } & Dinero en efectivo & Billetes de crédito & Total \\
\hline 3 junio & Jack Hermanos y Compañía & 8000 & 4000 & 12000 \\
\hline 3 junio & José Marcó del Pont & 3000 & 1500 & 4500 \\
\hline 4 junio & Andrés Viollier & 4000 & 1999 & 5999 \\
\hline 5 junio & Gibbs Crawley y Compañía & 6000 & 3000 & 9000 \\
\hline 9 julio & Rhomas Mac Laughlin & 2000 & 1000 & 3000 \\
\hline 19 julio & Andrés Viollier & 2000 & 1000 & 3000 \\
\hline 25 julio & Andrés Viollier & 1000 & 500 & 1500 \\
\hline 25 julio & Juan Moens & 1000 & 500 & 1500 \\
\hline 27 julio & Thomas Mac Laughlin & 2000 & 1000 & 3000 \\
\hline 22 agosto & Jack Hermanos y Compañía & 3000 & 1500 & 4500 \\
\hline 23 agosto & José Marcó del Pont & 1160 & 580 & 1740 \\
\hline 23 agosto & Tayleur Mac Laughlin y Compañía & 2000 & 1000 & 3000 \\
\hline 23 agosto & Gibbs Crawley y Compañía & 2000 & 1000 & 3000 \\
\hline 23 agosto & Dickson Price y Compañía & 300 & 150 & 450 \\
\hline 23 agosto & Andrés Viollier & 2000 & 1000 & 3000 \\
\hline
\end{tabular}

Fuente: El Republicano, tomo 15, No 71, Arequipa, 23 de septiembre de 1839.

\section{RELACIONES SOCIALES}

Para los Jack, esta clase de relaciones se dieron en un plano más bien económico antes que familiar, debido a que ninguno de los tres hermanos, Juan, Santiago y Carlos mientras estuvieron en Arequipa, contrajeron vínculos matrimoniales con damas de la élite local, lo mismo se puede decir de la mayoría de los socios y representantes de la firma. La mayor parte de sus miembros iniciales, después de amasar una relativa fortuna retornaron a Inglaterra y es allí donde contrajeron matrimonio. En definitiva, los únicos vínculos

${ }^{102}$ ARAR, Tesorería de Arequipa, Libro Manual 87, 16 de enero de 1849.

${ }^{103}$ ARAR, Tesorería de Arequipa, Libro Manual 87, 10 de marzo de 1849. 
de los hermanos Jack en su larga experiencia arequipeña, son aquellos que mantuvieron con sus homólogos extranjeros y casi siempre asociados al quehacer profesional. Aunque no por ello, estuvieron libres de antagonismos.

El dedicarse a un oficio similar (denominado "giro mercantil" en esa época), vender idénticos productos y, sobre todo, buscar como mercados, las mismas ciudades, provincias y regiones, necesariamente tuvieron que haber engendrado alguna forma de rivalidad entre los comerciantes extranjeros de la ciudad de Arequipa; por otro lado, aunque muchos se casaron con mujeres locales ${ }^{104}$ y establecieron su residencia en la región, no por ello lograron integrarse dentro de la sociedad local. Así lo observó también, a principios de la década de 1830, Eugenio de Sartiges, quien señalaba en sus memorias que "un europeo puede casarse con una arequipeña, pero siempre es un extranjero. Es un extranjero bueno o malo, más no se convierte por completo en hijo del país en uno de los suyos" ${ }^{105}$. En ese sentido, por razones de costumbre, idioma y religión tales individuos formaban una sociedad particular dentro de la gran comunidad arequipeña, muy a pesar de las posibles rivalidades comerciales que hayan surgido entre ellos.

A partir de estas consideraciones, se puede entender mejor la permanente vinculación de la Casa Jack con sus paisanos escoceses, algunos ingleses y europeos del norte, sobre todo cuando se trató de incorporar nuevos socios a la compañía ${ }^{106}$, encargar la administración de la dependencia de Tacna ${ }^{107}$, otorgar escrituras de fianza para poder desembarcar mercancías a nombre de terceros ${ }^{108}$, conceder poderes a representantes de la Casa con el objetivo de cobrar o demandar ${ }^{109}$ y hasta, cuando se buscaba algún testimonio confiable con la intención de justificar algún reclamo ${ }^{110}$.

${ }^{104}$ Samuel Haigh, comerciante inglés, vivió en Arequipa entre 1825 y 1827, manifestó: “durante mi residencia de diez y nueve meses, casi la mitad de los ingleses (veinte en número) se habían casado o comprometido con damas arequipeñas". Haigh, op. cit., pp. 13-43. Posiblemente se refería a Samuel Mardon, quien se casó con María de la Candelaria García y Ureta, Juan Federico Johnson primero con María Cáceres y Quezada y al enviudar con Agustina Ureta, Juan Moens con Paula Prado Zavalaga, Federico Marriot con Bernardina Rivero y Besoaín, Samuel Went con Juana Chocano, Juan Robinson con Rosalía Velarde, Anton von Lotten con María Sierra, al enviudar se casó con Heinrich Witt y Cristóbal Guillermo Schütte con Rosa von Lotten Sierra, por nombrar algunos.

${ }^{105}$ Sartiges, op. cit., p. 156.

${ }^{106}$ Aunque a lo largo de su historia la Casa Jack, cambió de socios varias veces (Guillermo Macandrew, Carlos Church, Santiago Ryder y Guillermo Enrique Fletcher), todos fueron escoceses.

${ }^{107}$ La sucursal de la casa de comercio de Tacna (1852-1863) fue administrada por Guillermo Macandrew, Jorge Stafford, Guillermo Ricketts y Santiago Ryder.

108 "Fianza. Don Juan Jack y Don Federico Marriot de este comercio... por cuanto en el puerto de Islay se halla anclada la fragata Bentolen procedente de Valparaíso a consignación su cargamento del enunciado Don Juan, se presentó al señor General Prefecto de este departamento pidiendo se le diese permiso para ello, bajo la calidad de dar la respectiva fianza, para responder a los cargos que se le hagan por esta aduana", en ARAR, Protocolos Notariales, Manuel Primo de Luque 725, fol. 615. También, en ARAR, Protocolos Notariales, Mariano Polar 792, fol. 29.

109 "Poder. Los señores Wyllie Jack y Compañía del comercio de esta a Don Guillermo Turner residente en la ciudad del Cusco", en ARAR, Protocolos Notariales, Juan Nepomuceno Zegarra 913, fol. 23. "Poder. Don Santiago Jack, natural de Escocia y residente de ejercicio comerciante como socio de la casa de Jack Hermanos y Compañía a Don Diego Guillermo Matheus residente en la ciudad del Cusco", en ARAR, Protocolos Notariales, Juan Mariano Polar 797, fol. 360.

110 "Reconocimiento y protesta. Los señores Don Juan Jack, Don Juan Robinson, Don Guillermo Turner, Don Federico Marriot, Don Santiago Le Bris y Don Justo Aparicio, del comercio de esta ciudad... habiendo 
Aunque los documentos notariales registran numerosos poderes a vecinos de la localidad, estos se enmarcan dentro del plano profesional, es decir, con frecuencia responden a las necesidades de la firma. Como el cobro de deudas o la representación legal, "para todos los pleitos, causas y negocios que tenga en los juzgados y tribunales" Los únicos casos que escapan a este mundo de los negocios, donde se hallaban inmersos los Jack son aquellas escrituras de fianzas otorgadas a favor de la liberación de algunos individuos presos en las cárceles de Arequipa, comprometiéndose a responder por sus personas ${ }^{112}$. Además, de las escrituras de depósito en favor de algunos vecinos de la ciu$\operatorname{dad}^{113}$.

Con respecto a la posible rivalidad entre las firmas Jack (Liverpool) y Gibbs (Londres), se puede considerar que se trató de una competencia bastante normal entre las dos mayores casas importadoras de la región; aunque no se conocen denuncias, agresiones y saboteos entre ellos, esta rivalidad llegó a traspasar el plano comercial. Cuando en 1847 el gobierno peruano anunció la revisión de los contratos de arrendamiento del guano y la introducción del sistema de consignaciones, Santiago Jack, quien en ese momento se encontraba fuera del Perú, regresó a inicios de 1848, con un respaldo financiero de más de un millón de pesos. Muy a pesar del esfuerzo, terminó con un amargo sabor de boca, cuando se enteró que los principales contratos de consignación al mercado de Inglaterra, el más lucrativo de todos, "habían sido asignados a su gran rival Gibbs y Compañía"114. Después de este fracaso, los Jack no insistirían más con el tema del guano, ni siquiera cuando el gobierno peruano canceló los acuerdos con Gibbs y entregó el negocio del fertilizante a nuevos empresarios nacionales (los "hijos del país") y extranjeros, como los conocidos Witt, Schütte y Compañía. Eso sí, continuarían con las lucrativas exportaciones de lana de camélidos a Europa y a la cabeza del comercio arequipeño. Como diría por esa época Heinrich Witt, antiguo empleado de la firma londinense, "la casa [Jack] en Arequipa continúa creciendo aún más que de los Gibbs"115. El siguiente cuadro sobre los derechos adeudados en la Aduana de Islay, por concepto de importaciones, respalda en cierta medida las siempre agudas observaciones del viajero y comerciante alemán.

pasado en la mañana de este día a la casa almacén de Don Daniel Schütte a pedimento de su apoderado Don Cristóbal Guillermo Schütte y con asistencia de el escribano, a efecto de hacer un formal reconocimiento de ciertos zurrones de añiles en el número de 86 de una partida de 11", en ARAR, Protocolos Notariales, Mariano Polar 792, fol. 154.

111 "Poder. Don Tomás Remy representante de la casa de comercio de los señores Guillermo Gibbs y Compañía, Don Jerónimo Guillermo Harmsen, Don Guillermo Macandrew, representante de la casa de los Hermanos Jack y Compañía, Don Luis Braillard y Don Diego Kendall de la de Bates L'Tokes y Compañía, todos vecinos comerciantes y mayores de edad al procurador Don Mariano Escolástico Tapia”, en ARAR, Protocolos Notariales, Isidoro Cárdenas 558, fol. 60.

112 "Fianza. Don Santiago Jack vecino y del comercio, hallándose preso por orden del señor Prefecto del departamento, Don Mariano López vecino del distrito de Yanque, en Caylloma", en ARAR, Protocolos Notariales, Juan Nepomuceno Pastor 765, Folios 6 y 195. También, ARAR, Protocolos Notariales, Cipriano Cervantes 575, fol. 280.

113 "Depósito. Don Manuel del Carpio apoderado de Doña Manuela Benavides... sobre un cargo de cantidad de pesos los mismo que han sido recibidos por Don Carlos Jack vecino y del comercio", en ARAR, Protocolos Notariales, Juan Nepomuceno Pastor 772, fol. 312.

${ }^{114}$ Este extracto fue tomado de Mills, op. cit., pp. 26-27.

${ }^{115}$ Witt, op. cit., vol. I, pp. 61-62. 
CuAdro $\mathrm{N}^{\mathrm{o}} 10$

Relación de deudores a la Aduana de Islay por derechos de importación, 1849-1855 (en pesos)

\begin{tabular}{|l|r|r|r|r|r|r|}
\hline \multicolumn{1}{|c|}{ Comerciante } & $\mathbf{1 8 4 9}$ & $\mathbf{1 8 5 0}$ & $\mathbf{1 8 5 1}$ & $\mathbf{1 8 5 2}$ & $\mathbf{1 8 5 4}$ & \multicolumn{1}{c|}{$\mathbf{1 8 5 5}$} \\
\hline Jack, Hermanos y Compañía & 59592 & 41647 & 75333 & 51280 & 20674 & 34184 \\
\hline Guillermo Gibbs y Compañía & 63985 & 40335 & 56333 & 63495 & 24014 & 29090 \\
\hline Guillermo Harmsen y Compañía & 21525 & 11564 & 6144 & 28862 & 16266 & 17324 \\
\hline Viollier/ Braillard y Compañía & 12344 & 5856 & 24534 & 34028 & 7435 & 12205 \\
\hline Cristóbal G. Schütte y Compañía & - & 169 & 6462 & 19594 & 5428 & 3092 \\
\hline Thomas Mac Laughlin y Compañía & 976 & 7295 & 8259 & 15097 & 4983 & 12156 \\
\hline
\end{tabular}

Fuente: ARAR, Tesorería de Arequipa, años 1849-1955.

\section{CONCLUSIONES}

Al inicio de este trabajo de investigación se propuso comprender un poco más acerca del comercio británico en Arequipa en la primera mitad del siglo XIX, a partir de las actividades de una de las casas comerciales más importantes establecidas en la ciudad, Jack, Hermanos y Compañía. Asimismo, se buscó explicar las razones o factores que pudieron haber estado detrás del éxito mercantil de esta empresa, en un periodo de expansión de las mismas e, incluso, con establecimientos que tuvieron vínculos comerciales mucho más sólidos. Al finalizar esta investigación, que no agota para nada este amplio y complejo tema, se puede aportar algunas conclusiones.

En primer lugar, la apertura del mercado arequipeño al capital británico fue obra de una avanzadilla de pioneros empresarios, denominados por D. C. M. Platt "comerciantes aventureros", como Guillermo Turner, Roberto Page, Guillermo Hodgson y Thomas Crompton, muchos de los cuales arribaron como sobrecargos de algunos navíos o consignatarios de casas comerciales ya establecidas en Londres o Liverpool. Ellos fueron los primeros en tomar posesión del comercio local y remitir al extranjero sus crecientes ganancias en forma de metales preciosos; en la práctica, inundaron hasta la saturación el mercado con efectos importados hasta por los menos 1828 , fecha en que, por un lado, comenzaron a desaparecer los mencionados y, por el otro, emergieron las grandes casas comerciales como: Gibbs Crawley, Tayleur Mac Laughlin, Dickson Price, Marriot Turner y la Casa Jack (aún no se llamaba Jack Hermanos), quienes más afiatados y con mayores conocimientos de la realidad económica, geográfica y cultural de la región, tomaron el control de las actividades comerciales y empresariales por el resto del siglo.

Asimismo, se debe señalar que, aunque, por lo general, las grandes casas comerciales arequipeñas compartían el mercado local y expendían similares productos como: tejidos diversos, licores finos, papel, muebles, alimentos en conserva, hierro y prendas de vestir (no se ha encontrado algún negocio especializado en un producto exclusivo), mayormente al crédito, cobrando entre el $1 \frac{1}{2} \%$ y $1 \%$ de interés mensual y con sus tiendas-almacén ubicadas en las proximidades de la plaza de Armas de la ciudad; el mayor o menor éxito estuvo relacionado con la forma particular como se administró el negocio. 
Aunque no por ello debe soslayarse la importancia que tuvo para una sucursal arequipeña, el respaldo financiero y comercial de una poderosa casa matriz como, por ejemplo, la Casa Gibbs y más aún, si a partir de 1849 ella obtuvo las consignaciones de guano para el mayor mercado del mundo, Inglaterra. Pero en ese caso los beneficiados fueron los dueños de la firma, los señores Gibbs de Londres, no sus administradores locales, en su mayoría asalariados.

En relación con lo anterior, una de las claves del éxito de Jack Hermanos, así como de otras casas arequipeñas ${ }^{116}$, estuvo en la administración directa del negocio por parte de los propios dueños; porque ello permitía ahorrar no solo varios miles de pesos correspondientes al salario de un administrador o tener un control permanente del mismo, vale decir: de las mercancías, las ventas, los precios, la demanda, las quejas y hasta el cobro de deudas sino, también, poder invertir de manera rápida en algún negocio ocasional y lucrativo, como la compra de una vivienda o terreno a precios rebajados, y en los montos que sean necesarios, sin la obligación de esperar varios meses por la aprobación o rechazo de los socios principales en Lima, Valparaíso o Inglaterra.

Por otro lado, las ventas de la firma Jack no incluían solo a individuos de la ciudad, donde la disputa con otras casas debió haber sido bastante intensa sino, también, a vecinos de distintas ciudades y pueblos ubicados en las provincias altas como: Condesuyos, Caylloma, la Unión, Sicuani, Maranganí y Parinacochas. Las tres primeras pertenecientes al departamento de Arequipa y las restantes a Puno, Cuzco y Ayacucho. Estas provincias no deben ser vistas solo como mercados para la venta de efectos, también fueron centros de producción de materias primas como metales preciosos y lana de camélidos. Con respecto a los metales preciosos, aunque los datos oficiales hablan de una crisis productiva durante esta época, es también cierto que entre 1825 y 1850 , de las ciento doce compañías o sociedades que se formaron en la región, casi la mitad fueron empresas mineras para explotar pequeños yacimientos ubicados en muchas de estas provincias $^{117}$. Ello explica, por un lado, los grandes volúmenes de metales preciosos enviados a Europa por la Casa Jack y, por el otro, que no toda la plata y oro producido en la región terminaba asentándose en los registros de minería sino, en los libros de aduanas.

${ }^{116}$ Un caso parecido al de Jack Hermanos, tal vez unos puntos por debajo, fue el de Santiago Le Bris, quien abrió la primera casa extranjera en Arequipa en 1821 y después de casi veinte años de trabajo intenso regresó a Francia, dejando el negocio a su empleado Andrés Viollier, quien la expandió aún más y en 1850, retornó también a Francia en posesión de una considerable fortuna, dejando la casa a su compatriota Luis Braillard, suizo como él. Este último decidió asentarse en Arequipa y sus descendientes continúan residiendo en el Perú. Véase Condori, "El francés Santiago Le Bris...”, op. cit., pp. 261-283.

${ }^{117}$ En un reciente trabajo sobre las sociedades económicas en Arequipa durante la primera mitad del siglo XIX, se encontró que el $48 \%$ de ellas estuvieron relacionadas con la explotación de oro y plata y solo el $18 \%$ con el comercio: Víctor Condori, "Economía y empresa en Arequipa a inicios de la República, 1825-1850", en Economía, vol. xxxviI, N²74, Lima, 2014, pp. 163-212. 